Commentary

\title{
Transmission of SARS-CoV-2 by children and young people in households and schools: A meta-analysis of population-based and contact-tracing studies
}

\author{
Russell Viner $^{\mathrm{a}, *}$, Claire Waddington ${ }^{\mathrm{b}}$, Oliver Mytton ${ }^{\mathrm{b}}$, Robert Booy ${ }^{\mathrm{c}}$, Joana Cruz ${ }^{\mathrm{a}}$, \\ Joseph Ward ${ }^{a}$, Shamez Ladhani ${ }^{\mathrm{d}}$, Jasmina Panovska-Griffiths ${ }^{\mathrm{e}}$, Chris Bonell ${ }^{\mathrm{f}}$, \\ G.J. Melendez-Torres ${ }^{\mathrm{g}}$ \\ a Population, Policy and Practice, UCL Great Ormond St. Institute of Child Health, London, United Kingdom \\ ${ }^{\mathrm{b}}$ University of Cambridge, United Kingdom \\ ${ }^{c}$ University of Sydney, Australia \\ d Public Health England, United Kingdom \\ e University of Oxford, United Kingdom \\ ${ }^{\mathrm{f}}$ London School of Hygiene and Tropical Medicine, United Kingdom \\ $\mathrm{g}$ University of Exeter Medical School, United Kingdom
}

\section{A R T I C L E I N F O}

\section{Article history:}

Accepted 18 December 2021

Available online $\mathrm{xxx}$

\section{S U M M A R Y}

Background: The role of children and young people (CYP) in transmission of SARS-CoV-2 in household and educational settings remains unclear. We undertook a systematic review and meta-analysis of contact-tracing and population-based studies at low risk of bias.

Methods: We searched 4 electronic databases on 28 July 2021 for contact-tracing studies and populationbased studies informative about transmission of SARS-CoV-2 from 0 to 19 year olds in household or educational settings. We excluded studies at high risk of bias, including from under-ascertainment of asymptomatic infections. We undertook multilevel random effects meta-analyses of secondary attack rates (SAR: contact-tracing studies) and school infection prevalence, and used meta-regression to examine the impact of community SARS-CoV-2 incidence on school infection prevalence.

Findings: 4529 abstracts were reviewed, resulting in 37 included studies (16 contact-tracing; 19 population studies; 2 mixed studies). The pooled relative transmissibility of CYP compared with adults was 0.92 $(0.68,1.26)$ in adjusted household studies. The pooled SAR from CYP was lower $(p=0.002)$ in school studies $0.7 \%(0.2,2.7)$ than household studies $(7.6 \%(3.6,15.9)$. There was no difference in SAR from CYP to child or adult contacts. School population studies showed some evidence of clustering in classes within schools. School infection prevalence was associated with contemporary community 14-day incidence (OR 1.003 (1.001, 1.004), $p<0.001$ ).

Interpretation: We found no difference in transmission of SARS-CoV-2 from CYP compared with adults within household settings. SAR were markedly lower in school compared with household settings, suggesting that household transmission is more important than school transmission in this pandemic. School infection prevalence was associated with community infection incidence, supporting hypotheses that school infections broadly reflect community infections. These findings are important for guiding policy decisions on shielding, vaccination school and operations during the pandemic.

(C) 2021 The Author(s). Published by Elsevier Ltd on behalf of The British Infection Association. This is an open access article under the CC BY-NC-ND license (http://creativecommons.org/licenses/by-nc-nd/4.0/)

\footnotetext{
* Corresponding author.

E-mail address: r.viner@ucl.ac.uk (R. Viner).
} 


\section{Background}

The role of children and young people (CYP) in transmission of SARS-CoV-2 remains unclear, in both households and child-specific settings, such as schools and nurseries. ${ }^{1}$ Observations of low incidence of symptomatic infection in CYP early in the pandemic led to assumptions that they played a very limited role in infection or transmission. This view has been challenged by the recognition that high proportions of asymptomatic infections in CYP led to low ascertainment of infections in this age-group, ${ }^{1}$ particularly when testing capacity was limited. Findings from some large contacttracing studies (contact-tracing studies) ${ }^{2}$ have suggested CYP do play an important role in household transmission. In educational settings, whilst outbreaks have been reported in day-care nurseries, ${ }^{3}$ schools ${ }^{4-6}$ and school-like residential camps, ${ }^{7,8}$ a number of population-based school studies have found evidence of limited transmission especially between children. ${ }^{9,10}$ It remains unclear the extent to which cases and outbreaks in schools reflect transmission in schools or the wider community.

Epidemiological studies that can provide useful information about transmission with the lowest risk of bias include contacttracing studies with active follow-up and testing of all contacts regardless of symptoms and population-based studies which test all members of the population regardless of symptoms. Populationbased studies are informative about prevalence across age-groups and risk factors for infection, and may provide information about clustering or timing of infection within a setting (e.g. households or schools). Studies have shown that children under 1012 years have lower susceptibility to SARS-CoV-2 infection than adults, although the risk in teenagers appears to be closer to young adults. ${ }^{11}$ However CYP also tend to have the highest social mixing rates across society, including during the pandemic, ${ }^{12}$ and transmission is a complex interaction of viral properties, susceptibility, social mixing and population age structures. For these reasons, studies of incidence of symptomatic infection in CYP provide a weak basis for inference around children's role in transmission. ${ }^{11}$

Over 18 months into the COVID-19 pandemic, there are only now sufficient data to allow meta-analysis of relevant data only including studies at low risk of bias. Existing systematic reviews are now outdated, including only data from early in the pandemic, ${ }^{13-18}$ and are critically biased by their inclusion of studies which systematically under-ascertained asymptomatic infections in CYP. A large literature has since been published, including several populationbased studies of CYP within schools. ${ }^{9,10}$ Many of these date from late 2020 or early 2021 when schools had extensive mitigation measures in place that are hypothesized to reduce transmission within schools, as does reducing attendance during periods of hybrid in-person and online learning, yet data on the effects of such measures are lacking. ${ }^{19,20}$

We undertook a systematic review and meta-analysis of high quality epidemiological studies published during the first 18 months of the pandemic (Jan 2020- July 2021) to answer the following questions: (a) To what extent do CYP under 20 years of age transmit SARS-CoV-2 to other CYP and to adults in household and child-specific (e.g. educational) settings?; (b) how does transmission differ between household and educational settings?; and (c) is community infection incidence associated with prevalence of or transmission of infection within educational settings?

\section{Methods}

The search was undertaken using a protocol registered with Prospero registry (CRD42021222276).
Search strategy

We searched four electronic databases (PubMed; medRxiv; COVID-19 Living Evidence database; Europe PMC) to 28 July 2021. The search terms for PubMed were ("COVID-19" [Text Word] OR "2019-nCoV" [Text Word] OR "SARS-CoV-2" [Text Word]) AND ("child*" [All Fields] OR "infant*" [All Fields]) AND ("disease transmission, infectious" [MeSH Terms] OR "epidemiology" [MeSH Terms] OR "schools" [MeSH Terms]) with terms for other databases shown in Appendix Table 1.

We defined children and young people as being $<20$ years of age, but note that different studies used different age-ranges across childhood. We did not limit studies by date or language. The reference lists of identified relevant reviews were checked for additional likely studies. Studies were also identified through other systematic reviews and the professional networks of the authors.

\section{Eligibility}

We searched for contact-tracing studies and community incidence studies to answer questions a) and b), and school incidence or prevalence studies to answer question c). We included published or unpublished reports of studies of SARS-CoV-2 infection of the following types:

a. Contact-tracing studies informative about transmission from primary or index cases aged $0-19$ years separately to adult index cases and which identified and tested all contacts regardless of symptoms

b. Population-based studies that were either:

i. longitudinal incidence studies in any setting which reported or modelled transmission chains between 0 and 19 year olds and others

ii. studies of prevalence or incidence in 0-19 year olds in childspecific settings (e.g. day-care, nurseries or schools) using either longitudinal or cross-sectional designs

We only included studies which identified SARS-CoV-2 infection through RT-PCR on oral or nasal samples or through established serological methods. We did not include studies which used less well validated methods such as rapid antigen tests, stool samples ${ }^{21}$ or wastewater methods.

We excluded studies of transmission from single individuals or within single institutions; modeling studies that did not provide observational data; studies of vertical transmission; systematic reviews; studies only of school staff; and biological studies of transmission dynamics such as viral load, viral shedding or aerosolization. We excluded ecological level studies of the impact of school opening or closing on community transmission as this has been examined in a separate review. ${ }^{22}$

We excluded studies judged to be at critical risk of bias relating to inadequate ascertainment of asymptomatic infections in CYP. We, therefore, excluded:

1. contact-tracing studies which only tested symptomatic contacts, tested low proportions of recruited contacts or provided insufficient information to judge completeness of contact testing.

2. population studies where infection was identified only by testing of symptomatic individuals or recruitment from clinical settings

3. non-representative population studies due to limited sampling of the target population e.g. where testing was only performed in low proportions of participants

Study selection

Titles and abstracts of identified studies were reviewed for potential eligibility by one researcher (RV). Those potentially eligible 
Table 1

Study characteristics.

\begin{tabular}{|c|c|c|c|c|c|c|c|c|c|c|c|}
\hline Authors & Source & Site & Dates & Virus/ variant & $\begin{array}{l}\text { Case } \\
\text { identification }\end{array}$ & Study type & Setting and exposure & $\mathrm{N}$ & $\begin{array}{l}\text { Age of } \\
\text { CYP }\end{array}$ & Testing & Findings \\
\hline Blaisdell et al. & PubMed & USA & $\begin{array}{l}\text { June-August } \\
2020\end{array}$ & NS & Population & Contact-tracing & $\begin{array}{l}\text { Four residential summer } \\
\text { school camps for children } \\
\text { and staff. Mixture of } \\
\text { outdoor and indoor } \\
\text { activities. Approximately } \\
75 \% \text { of usual enrolment. }\end{array}$ & $\begin{array}{l}1022 \text { attendees from } 41 \text { US } \\
\text { states ( } 642 \text { children, } 380 \\
\text { staff); } 1006 \text { tested ( } 98 \%) \text {. } \\
\text { Attended from } 44 \text { to } 62 \\
\text { days. } 3 \text { primary cases and } \\
41 \text { contacts ( } 30 \text { children, } 11 \\
\text { staff) }\end{array}$ & 7-18y & $\begin{array}{l}\text { RT-PCR (swab site not } \\
\text { stated) before arrival, on } \\
\text { arrival and at } 4 \text { and } 9 \text { days }\end{array}$ & $\begin{array}{l}3 \text { attendees }(0.3 \%) \text { ( } 2 \text { staff, } 1 \\
\text { child) tested positive after } \\
\text { arrival and their cohorts } \\
(n=41 \text { contacts) isolated for } \\
8-14 d, \text { being released after } 2 \\
\text { negative tests. No secondary } \\
\text { cases in contacts in } 30 \text { contacts } \\
\text { of child primary and } 11 \text { contacts } \\
\text { of the } 2 \text { adult primary cases. }\end{array}$ \\
\hline Varma et al. & Professional & USA & $\begin{array}{l}\text { Period 19 } \\
\text { Oct-20 Nov; } \\
\text { Period 2: 6-18 } \\
\text { Dec 2020 }\end{array}$ & NS & $\begin{array}{l}\text { A) Population } \\
\text { and B) Infection }\end{array}$ & $\begin{array}{l}\text { A) Surveillance \& } \\
\text { B) Contact tracing }\end{array}$ & $\begin{array}{l}\text { A) Surveillance: Routine } \\
\text { testing of a random sample } \\
\text { CYP attending public } \\
\text { schools in New York City; } \\
12 \text { Oct-20 Nov: } 26 \% \text { of CYP } \\
\text { attended } 1-3 \text { days per } \\
\text { week with remainder } \\
\text { learning online; all schools } \\
\text { closed 19Nov- } 6 \text { Dec and } \\
\text { only elementary schools } \\
\text { reopened in Dec; B) } \\
\text { Routine public health data } \\
\text { from city database and } \\
\text { contact-tracing. Contacts } \\
\text { quarantined for } 14 \text { days. }\end{array}$ & $\begin{array}{l}\text { A) Surveiillance in schools: } \\
10-20 \% \text { of each school } \\
\text { selected: Period } 1: \\
n=60,783 \text { CYP (41\% of } \\
\text { eligible consent), Period 2: } \\
n=34,556 \text { CYP (61\% of } \\
\text { eligible consented); B) } \\
\text { Contact-tracing: } 22231 \text { cases } \\
\text { (child \& adult) linked with } \\
\text { schools and their } 36,423 \\
\text { school-based contacts } \\
\text { identified across entire } \\
\text { period. }\end{array}$ & $5-14 y$ & $\begin{array}{l}\text { RT-PCR (NP swab): A) } \\
\text { Monthly testing for all } \\
\text { schools with some schools } \\
\text { moving to weekly in } \\
\text { November and all primary } \\
\text { schools weekly in Dec. B) } \\
\text { RT-PCR testing of contacts } \\
\text { of identified cases. } \\
\text { Proportion of contacts } \\
\text { identified and tested not } \\
\text { stated - mean } 16.2 \text { contacts } \\
\text { per case tested }\end{array}$ & 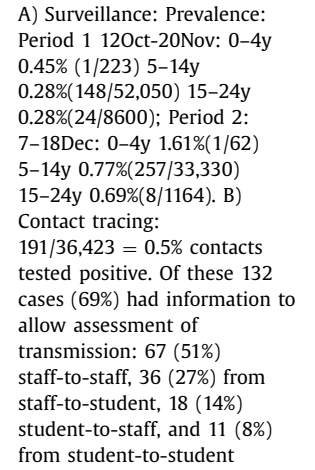 \\
\hline Park et al. & Handsearch & South Korea & $\begin{array}{l}20 \mathrm{Jan}-27 \mathrm{Mar} \\
2020\end{array}$ & NS & Infection & Contact-tracing & $\begin{array}{l}\text { Households. National Korea } \\
\text { Centers for Disease Control } \\
\text { contact-tracing database } \\
\text { used. High quality testing, } \\
\text { tracing and isolation } \\
\text { system. }\end{array}$ & $\begin{array}{l}10,962 \text { index cases }(29 \\
(0.5 \%) \text { aged } 0-9 y, 124 \\
(2.2 \%) 10-19 y) \text { and } 10,592 \\
\text { HH contacts (57 for } 0-9 y \\
\text { index; } 231 \text { for } 10-19 y \\
\text { index). Data on } \mathrm{HH} \\
\text { contacts only used, as all } \\
\text { HH contacts routinely } \\
\text { tested while other contacts } \\
\text { tested if symptomatic. }\end{array}$ & $0-19 y$ & $\begin{array}{l}\text { RT-PCR (swab site not } \\
\text { stated) }\end{array}$ & $\begin{array}{l}\text { SAR for } 0-9 y \text { index: } 5.3 \%(1.3 \text {, } \\
13.7 ; 3 / 57) \text {. SAR for } 10-19 y \\
\text { index: } 18.6 \%(14.0,24.0 ; 43 / 231) \text {. } \\
\text { Compared with } 10.5 \% \\
\text { (889/8440) in } 20-59 \text { year olds. }\end{array}$ \\
\hline Schoeps et al. & medRxiv & Germany & $\begin{array}{l}17 \text { Aug-16 Dec } \\
2020\end{array}$ & NS & Infection & Contact-tracing & $\begin{array}{l}\text { K-12 schools in } 1 \text { state } \\
\text { (Rhineland-Palatinate): FTF. } \\
\text { Data from school reopening } \\
\text { in August } 2020 \text { through to } \\
\text { lockdown on } 16 \text { Dec } 2020\end{array}$ & $\begin{array}{l}\text { Population: } 1492 \text { schools, } \\
406,607 \text { schoolchildren \& } \\
144,245 \text { children }<6 \text { years } \\
\text { in day-care. } 784 \text { index } \\
\text { cases notified; information } \\
\text { on contacts available on } \\
441 \text { index cases } 346 \\
\text { students, } 91 \text { staff, } 20 \\
\text { unknown) with } 14,591 \\
\text { contacts of whom } 13,005 \\
\text { were tested contacts. }\end{array}$ & $3-18 y$ & $\begin{array}{l}\text { Public health notification of } \\
\text { PCR+cases (NP swab) } \\
\text { linked to educational } \\
\text { institutions; all close } \\
\text { contacts offered PCR } \\
\text { testing routinely - 89\% of } \\
\text { contacts (87\% of child } \\
\text { contacts) were PCR-tested } \\
\text { (13,005 contacts). } \\
\end{array}$ & $\begin{array}{l}\text { When restricted to PCR-tested } \\
\text { contacts ( } 441 \text { index cases \& } \\
13,005 \text { contacts), overall IAR } \\
\text { was } 1 \cdot 51(1 \cdot 30-1 \cdot 73) \text {; SAR from } \\
\text { children } \\
99 / 10,716=0.92(0.75-1.12) \text {. } \\
\text { These } 99 \text { secondary cases } \\
\text { occurred in } 53 \text { clusters of } 3 \\
\text { cases or more; SAR from } \\
\text { teachers } \\
91 / 2858=3.18(2.57-3.90) ; \\
\text { transmission from teacher index } \\
\text { was greater than from child } \\
\text { index IRR } 4.4 p<0.001 ; \\
\text { calculated each teacher index } \\
\text { resulted in } 0.5 \text { secondary cases, } \\
\text { whereas there was only } 1 \\
\text { teacher secondary for } 25 \text { child } \\
\text { indexes. }\end{array}$ \\
\hline
\end{tabular}

(continued on next page) 
Table 1 (continued)

\begin{tabular}{|c|c|c|c|c|c|c|c|c|c|c|c|}
\hline Authors & Source & Site & Dates & Virus/ variant & $\begin{array}{l}\text { Case } \\
\text { identification }\end{array}$ & Study type & Setting and exposure & $\mathrm{N}$ & $\begin{array}{l}\text { Age of } \\
\text { CYP }\end{array}$ & Testing & Findings \\
\hline Hu et al. & $\begin{array}{l}\text { medRxiv then } \\
\text { published }\end{array}$ & $\begin{array}{l}\text { China } \\
\text { (Hunan) }\end{array}$ & $\begin{array}{l}13 \text { Jan-2 April } \\
2020\end{array}$ & NS & Infection & Contact-tracing & $\begin{array}{l}\text { Households in Hunan } \\
\text { province }\end{array}$ & $\begin{array}{l}1178 \text { index cases ( } 61 \text { aged } \\
0-14 y \text { ) and } 15,648 \text { close } \\
\text { contacts }(1706 \text { aged } \\
0-14 y): 471 \text { secondary } \\
\text { cases }\end{array}$ & $\begin{array}{l}\text { Children } \\
\text { \& adults: } \\
\text { child age } \\
<15 \mathrm{y}\end{array}$ & $\begin{array}{l}\text { Hunan Province CDC } \\
\text { dataset: all contacts } \\
\text { quarantined for } 14 \text { days } \\
\text { and tested regardless of } \\
\text { symptoms }\end{array}$ & $\begin{array}{l}\text { Age-related transmission could } \\
\text { be examined in } 461 \text { index cases } \\
(250-14 y) \text {. Unadjusted } 0 R \text { for } \\
\text { secondary infection from } 0 \text { to } \\
14 y 0 \text { 0.33(0.04, } 2.83) \text { compared } \\
\text { with } 15-64 y \text { yo, however small } \\
\text { numbers of index children } \\
\text { (25/461 } 5 \% \text {. In adjusted } \\
\text { general linear models, this } \\
\text { association was again not } \\
\text { significant }(0.28(0.04,2.04) \text {. }\end{array}$ \\
\hline Dattner et al. & $\begin{array}{l}\text { medrxiv then } \\
\text { published }\end{array}$ & Israel & $\begin{array}{l}17 \text { Mar-3 May } \\
2020\end{array}$ & NS & Population & Contact-tracing & $\begin{array}{l}637 \mathrm{HH} \text { in Bnei Brak, Israel } \\
\text { where all HH members } \\
\text { were tested. Note } 51 \% \text { of } \\
\text { population }<20 \mathrm{y} \text {. }\end{array}$ & $\begin{array}{l}3353 \text { (1809 adults and } \\
1544 \text { children } 0-19 y)\end{array}$ & $0-19 y$ & $\begin{array}{l}\text { RT-PCR (site not stated) all } \\
\text { HH contacts; Serology IgG } \\
\text { in } 130 / 637 \mathrm{HH}\end{array}$ & $\begin{array}{l}\text { Joint PCR \& serology } \\
\text { transmission mode: Relative } \\
\text { susceptibility of }<20 y \text { compared } \\
\text { with adults was } 43 \% \text { (31\%, 55\%) } \\
\text { and relative } \\
\text { transmissibility/infectivity } \\
63 \%(37,88) \text {. Positive PCR: } \\
\text { excluding index cases, } 44 \% \text { of } \\
\text { adults were infected compared } \\
\text { to } 25 \% \text { of the children. Serology } \\
\text { positive: }<20 y=34 \% \text { (141/417), } \\
\text { adults= } 48 \%(137 / 288)\end{array}$ \\
\hline Yoon et al. & $\begin{array}{l}\text { medrxiv then } \\
\text { published }\end{array}$ & South Korea & $\begin{array}{l}20 \text { May-31 July } \\
2020\end{array}$ & NS & Infection & Contact-tracing & $\begin{array}{l}\text { National school } \\
\text { surveillance data from } \\
\text { test-trace system. Schools } \\
\text { resumed FFF learning in } 4 \\
\text { steps from } 20 \text { May (Year } 12 \\
\text { only) through to } 8 \text { June. } \\
\text { Efficient test-trace system } \\
\text { with testing of all contacts }\end{array}$ & $\begin{array}{l}44 \text { index children and } \\
>13,100 \text { contacts attending } \\
38 \text { schools/EYS: } 6 \\
\text { EYS(4-5y), } 17 \text { primary } \\
\text { school(7-12y), } 6 \text { middle } \\
\text { school (13-15y) and } 15 \\
\text { high school ( } 16-18 \mathrm{y}) \text {. } \\
\text { Contacts: } 875 \text { YES, } 3374 \\
\text { primary, } 1525 \text { middle and } \\
6255 \text { high school. All } \\
\text { contacts tested;\% } \% \text { contacts } \\
\text { participating not stated } \\
\text { however tested mean } 297 \\
\text { contacts per index }\end{array}$ & $4-18 y$ & $\begin{array}{l}\text { RT-PCR (swab, siting not } \\
\text { stated) }\end{array}$ & $\begin{array}{l}\text { SAR (children and adults) from } \\
\text { child index cases: total } \\
\text { 1/13,100: EYS 0\%(0/875), } \\
\text { primary } 0.03 \%(1 / 3374) \text {, middle } \\
\text { and high } 0 \%(0 / 7780) \text {. Identified } \\
\text { source for } 29 / 44 \text { child index } \\
\text { cases: } 79 \%(23) \text { infected by } \\
\text { family members. }\end{array}$ \\
\hline Li et al. & $\begin{array}{l}\text { medrxiv then } \\
\text { published }\end{array}$ & $\begin{array}{l}\text { China } \\
\text { (Wuhan) }\end{array}$ & $\begin{array}{l}2 \text { Dec 2019-18 } \\
\text { Apr } 2020\end{array}$ & NS & Infection & Contact-tracing & $\begin{array}{l}\text { Retrospective regional data } \\
\text { from Wuan Center for } \\
\text { Disease Control and } \\
\text { Prevention system. }\end{array}$ & $\begin{array}{l}29,578 \text { primary cases in } \\
29,405 \mathrm{HH} \text { and } 57,581 \mathrm{HH} \\
\text { contacts. Test data were } \\
\text { available for } 48,962 \\
\text { contacts ( } 85 \% \text {; data missing } \\
\text { for remainder \& unclear if } \\
\text { tested or not; all HH } \\
\text { contacts tested after } 2 \text { Feb } \\
\text { but not before). For HH } \\
\text { with a single primary case, } \\
\text { there were } 24,985 \text { index } \\
\text { cases ( } 327 \text { were }<20 \mathrm{y} \\
(1.3 \%) \text { and } 52,822 \text { contacts. } \\
\text { Note that non-tested } \\
\text { contacts were assumed to } \\
\text { be negative }\end{array}$ & $0-19 y$ & $\begin{array}{l}\text { RT-PCR (swab site not } \\
\text { stated) }\end{array}$ & $\begin{array}{l}\text { SAR for primary cases }<20 \mathrm{y} \\
5.8 \%(4.3,7.7 ; 46 / 793) . \\
\text { Unconditional GEE models } \\
\text { suggested lower transmissibility } \\
\text { for }<20 \mathrm{y}(\mathrm{OR} 0 \cdot 66(0 \cdot 48-0 \cdot 90) \\
\text { compared with }>=60 \mathrm{y}) \\
\text { whereas conditional } \\
\text { chain-binomial models } \\
\text { suggested higher infectivity for } \\
<20 \mathrm{y} \text { (OR } 1 \cdot 58(1.28,1.95) \\
\text { compared with }>=60 \mathrm{y}\end{array}$ \\
\hline
\end{tabular}




\begin{tabular}{|c|c|c|c|c|c|c|c|c|c|}
\hline Authors & Source & Site & Dates & Virus/ variant & $\begin{array}{l}\text { Case } \\
\text { identification }\end{array}$ & Study type & Setting and exposure & $\mathrm{N}$ & $\begin{array}{l}\text { Age of } \\
\text { CYP }\end{array}$ \\
\hline $\begin{array}{l}\text { Laxminarayan } \\
\text { et al. }\end{array}$ & $\begin{array}{l}\text { medrxiv then } \\
\text { published }\end{array}$ & India & $\begin{array}{l}\text { 5 Mar-June } \\
2020\end{array}$ & NS & Infection & Contact-tracing & $\begin{array}{l}\text { Community and HH CTS of } \\
\text { state national } \\
\text { surveillance-identified } \\
\text { positive cases in Andhra } \\
\text { Pradesh and Tamil Nadu }\end{array}$ & $\begin{array}{l}\text { Index cases } 6063 \\
<18 \mathrm{y}+78,866 \text { adults; } \\
\text { contacts } 57,415 \\
<18 \mathrm{y}+507,476 \text { adults. All } \\
\text { recruited contacts tested. } \\
20 \% \text { of reported cases } \\
\text { included and } 19 \% \text { of traced } \\
\text { contacts participated }\end{array}$ & $<18 \mathrm{y}$ \\
\hline Larosa et al. & Professional & Italy & $\begin{array}{l}1 \text { Sep-15 Oct } \\
2020\end{array}$ & NS & Infection & Contact-tracing & $\begin{array}{l}\text { Schools and early years } \\
\text { settings in Reggio Emilia } \\
\text { province after reopening of } \\
\text { schools. Schools reopened } \\
15 \text { Sep, very largely FTF } \\
\text { although some large } \\
\text { schools operated 50\% } \\
\text { hybrid teaching if } \\
\text { classrooms don't allow } \\
\text { distancing }\end{array}$ & $\begin{array}{l}48 \text { index cases ( } 43 \\
\text { children, } 5 \text { staff) identified } \\
\text { in } 41 \text { classes of } 36 \text { schools; } \\
1198 / 1200 \text { contacts tested } \\
\text { (99.8\%; } 994 \text { children, } 204 \\
\text { staff) }\end{array}$ & $0-19 y$ \\
\hline Macartney et al. & Professional & Australia & $\begin{array}{l}4 \text { July - } 18 \text { Dec } \\
\text { 2020: Term3 }(4 \\
\text { July-25 Sep), } \\
\text { Term } 4 \text { (26 } \\
\text { Sep-18 Dec). }\end{array}$ & $\begin{array}{l}\text { WT; no VOC } \\
\text { detected }\end{array}$ & Infection & Contact-tracing & $\begin{array}{l}\text { State-wide surveillance of } \\
\text { cases identified attending } \\
\text { schools in New South } \\
\text { Wales while infectious. } \\
\text { Schools fully open FF; } 88 \% \\
\text { attendance Term } 3 \text { and } 4 \text {. }\end{array}$ & $\begin{array}{l}\text { RT-PCR. Term } 3: 39 \\
\text { primary cases ( } 32 \text { students, } \\
7 \text { staff) and } 3641 \text { contacts: } \\
95 \% \text { of contacts tested. } \\
\text { Term } 4: 10 \text { primary cases } \\
\text { (9 students, } 1 \text { staff) and } \\
1098 \text { contacts ( } 99 \% \\
\text { contacts tested) }\end{array}$ & $3-18 y$ \\
\hline
\end{tabular}

Testing

RT-PCR (site not stated). All $\quad$ SAR $=7.2 \%(4110 / 57,415)$ from 0 con 14 to $17 y$ and $7.4 \%(37,479 / 507,476)$ at least once during at least once duing

RT-PCR - swab, site not stated. Cases identified through routine public health systems. Included a cases noted to have connection with schools in $48 \mathrm{H}$ before symptoms/test.

$$
\text { . }
$$

RT-PCR (Np swab). Note serology also conducted on small numbers - not reported here. 1098 contacts ( $99 \%$
contacts tested)

38 secondary cases in 9 clusters mongst children $(\mathrm{SAR}=3.8 \%$, $38 / 994)$ and no secondary cases shool SAR from child+adult secondary cases $38 / 1198)$. children in early years settings. SAR from children only only child index cases $n=14$ (1/266)

ERM 3: 33 secondary cases (28 (33/3641).

EYS: 6 primary cases (2 children, 4 staff): overall SAR 1.7\% (13/754); SAR from 2 child primary cases: SAR to children $0 \%(0 / 58)$, SAR to adults 0 Prim

Primary schools:13 primary cases (11 children, 2 staff) in
schools: SAR from child primary: SAR to children $0.3 \%$ (2/643) SAR to adults 0\% (0/76) Secondary schools: 20 primary cases (19 student, 1 staff): overall SAR 1.1\%(27/2466) - 1 student primary in 16 schools: SAR to students $1.27 \%(26 / 2045)$ SAR to adults $0.4 \%(1 / 226)$. TERM 4: 13 secondary cases (12 student, 1 staff) occurred in 4 overall SAR 12\% (13/1098).

EYS: 4 primary child cases (no adult) resulted in 4 secondary cases ( 3 children, 1 adult). SAR from child index: child $0.8 \%$ (3/393) adult $1.3 \%(1 / 79)$ Primary: 3 primary cases (2 children, 1 staff) in 3 schools: 9 secondary children, 0 secondary staff cases. SAR from child index: child $0.4 \%$ (1/269) adult Secondary: 3

Secondary: 3 primary children in 3 schools: 0 secondary cases
in 199 student and 43 staff contacts.

(continued on next page) 
Table 1 (continued)

\begin{tabular}{|c|c|c|c|c|c|c|c|c|c|c|c|c|}
\hline Authors & Source & Site & Dates & Virus/ variant & $\begin{array}{l}\text { Case } \\
\text { identification }\end{array}$ & Study type & Setting and exposure & $\mathrm{N}$ & $\begin{array}{l}\text { Age of } \\
\text { CYP }\end{array}$ & Testing & Findings & 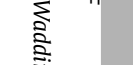 \\
\hline Kim et al. & PubMed & South Korea & $\begin{array}{l}20 \text { Jan-6-Apr } \\
2020\end{array}$ & NS & Infection & Contact-tracing & $\begin{array}{l}\text { HH contact-tracing study of } \\
\text { all confirmed cases } \leq 18 \\
\text { years in South Korea }\end{array}$ & $\begin{array}{l}\text { First } 107 \text { index cases } \leq 18 \mathrm{y} \\
\text { identified nationally and } \\
\text { their } 248 \mathrm{HH} \text { members } \\
\text { (defined as close contacts; } \\
\text { mean } 4.3 \text { per child) }\end{array}$ & $<18 \mathrm{y}$ & $\begin{array}{l}\text { RT-PCR (site not stated) of } \\
\text { all contacts (100\%); } \\
\text { quarantined for } 14 \mathrm{D}\end{array}$ & $\begin{array}{l}41 / 248(16.5 \%) \text { were positive } \\
\text { but } 40 \text { of these were assessed } \\
\text { to likely have the same initial } \\
\text { exposure as the child therefore } \\
\text { removed from total contact } \\
\text { number. O } 1 \text { definite secondary } \\
\text { case was identified from } \\
\text { index }<19 y \text { - SAR }=1 / 208=0.48 \\
\text { (reported in paper as } 0.4 \text { using } \\
\text { total contact number) }\end{array}$ & 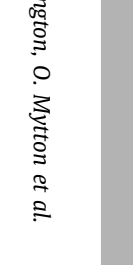 \\
\hline Verberk et al & $\begin{array}{l}\text { medRxiv; data } \\
\text { obtained from } \\
\text { authors }\end{array}$ & $\begin{array}{l}\text { Netherlands } \\
\text { \& Belgium }\end{array}$ & $\begin{array}{l}\text { Apr-December } \\
2020\end{array}$ & $\begin{array}{l}\text { WT; } \\
\text { recruitment } \\
\text { before VOC } \\
\text { circulating }\end{array}$ & Infection & Contact-tracing & $\begin{array}{l}\text { HH in Utrecht or Antwerp } \\
\text { recruited through a } \\
\text { positive index case in HH } \\
\text { with } 2 \text { or more members. } \\
\text { Households approached } \\
\text { after positive PCR test in } \\
\text { one member; not designed } \\
\text { to be representative of } \\
\text { broader population }\end{array}$ & $\begin{array}{l}272 \text { Households recruited. } \\
\text { Interim data in the } \\
\text { preprint provided on first } \\
117 \mathrm{HH} \text {. Data provided by } \\
\text { authors on } 39 \text { index cases } \\
\text { aged } 0-18 y \text { and their } 131 \\
\text { HH contacts. }\end{array}$ & $0-18 y$ & $\begin{array}{l}\text { RT-PCR (nasopharyngeal) } \\
\text { and serology IgG of all HH } \\
\text { members at baseline } \\
\text { (median Day } 5 \text { after index } \\
\text { diagnosis) and repeated if } \\
\text { symptomatic or for all } \\
\text { participants at D21. } \\
\text { Secondary infection defined } \\
\text { as PCR or seropositive }\end{array}$ & $\begin{array}{l}\text { Preprint findings: overall SAR } \\
27.9 \% \text { (95\%-CI: } 22.7-33.8 \%) \text {; SAR } \\
\text { highest from parent to child } \\
\text { (36.1\%) and lowest from child to } \\
\text { parent (15.7\%). Data supplied by } \\
\text { authors: infections from } 39 \\
\text { index children: SAR for } 0-11 \mathrm{y} \\
4.3 \%(2 / 47) \text { and } 12-18 y \text { 17.9\% } \\
(15 / 84)\end{array}$ & \\
\hline Brandal et al. & PubMed & Norway & $\begin{array}{l}28 \text { Aug-11 Nov } \\
2020\end{array}$ & NS & Infection & Contact-tracing & $\begin{array}{l}\text { Primary schools in } 2 \\
\text { counties with highest } \\
\text { prevalence }\end{array}$ & $\begin{array}{l}13 \text { child index cases } \\
\text { identified during period; } \\
292 \text { contacts (234 child; } 58 \\
\text { adults). Contact } \\
\text { participation was } 73 \% \text { child } \\
\text { \& } 78 \% \text { adult. }\end{array}$ & $5-13 y$ & $\begin{array}{l}\text { RT-PCR on saliva: Cases } \\
\text { were PCR+ } \& \text { attended } \\
\text { school within } 48 \mathrm{~h} \text { of } \\
\text { sample/symptom; } 2 \text { saliva } \\
\text { RT-PCR for all contacts: } \\
\text { immediate and at } 10 \text { days } \\
\text { of isolation }\end{array}$ & $\begin{array}{l}\text { All child index cases except } 1 \\
\text { had HH members who tested } \\
\text { positive before child. SAR from } \\
\text { child index cases }=0.9 \%(2 / 234) \\
\text { for children and } 1.7 \%(1 / 58) \text { for } \\
\text { adults }\end{array}$ & \\
\hline Reukers et al. & $\begin{array}{l}\text { medRxiv then } \\
\text { published }\end{array}$ & Netherlands & Mar-May 2020 & NS & Infection & Contact-tracing & $\begin{array}{l}\text { Households in Utrecht } \\
\text { region: all HH with a } \\
\text { positive adult and }<18 \text { h in } \\
\text { HH were contacted to } \\
\text { recruit entire } \mathrm{HH} \text {; studied } \\
\text { within } 24 \text { hrs of } \\
\text { recruitment;\% of eligible } \\
\text { indexes not stated }\end{array}$ & $\begin{array}{l}55 \mathrm{HH}: 242 \text { participants } \\
\text { (55 adult index cases, } 187 \\
\text { contacts }(70 \text { children } 1-11 \mathrm{y}, \\
46 \text { adolescents } 12-17 \mathrm{y}) . \\
\text { Entire households } \\
\text { participated. }\end{array}$ & $1-17 y$ & $\begin{array}{l}\text { RT-PCR (NP and oral } \\
\text { swabs) and serology for } \\
\text { entire HH } 3 \text { times - on } \\
\text { Days } 1,14-21 \text { and } 28-42 \text {. } \\
\text { Participation rate for } \\
\text { contacts not stated but } \\
\text { implied to be } 100 \%\end{array}$ & $\begin{array}{l}\text { In } 1 / 55 \mathrm{HH} \text { the primary case } \\
\text { was an adolescent and not the } \\
\text { index adult. No secondary cases } \\
\text { in } 17 \mathrm{HH} \text { and } 100 \% \text { secondary } \\
\text { infections in } 11 \mathrm{HH} \text {. Overall SAR } \\
43 \%(33,53) \text { : lower risk of } \\
\text { infection for } 1-11 \text { yo compared } \\
\text { with adults in adjusted models. } \\
\text { Adjusted SAR } 1-11 \mathrm{y} 35 \%(24,46), \\
12-18 \mathrm{y} 41 \%(27,56) \text { and } 18 y p \text { plus } \\
51 \%(39,63) \text {. } \\
\text { Transmission/susceptibility } \\
\text { model: susceptibility compared } \\
\text { to adults: } 1-11 \mathrm{y} 0.67(0.40,1.1) \\
12-17 \mathrm{y} 0.93(0.51,1.7) \text {. } \\
\text { Transmissibility compared with } \\
\text { adults: } 1-11 \mathrm{y} \text { 0.73(0.04, 2.6) } \\
12-17 \mathrm{y} 2.7(0.98,5.6)\end{array}$ & \\
\hline Lyngse et al. & medRxiv & Denmark & $\begin{array}{l}25 \text { Aug 2020-10 } \\
\text { Feb 2021 }\end{array}$ & NS & $\begin{array}{l}\text { Infection/ } \\
\text { Population }\end{array}$ & Contact-tracing & $\begin{array}{l}\text { Danish population register } \\
\text { linked with national testing } \\
\text { database, including all } \\
\text { contact-tracing data. } \\
\text { Reconstructed HH and } \\
\text { identified transmission } \\
\text { chains using time data. } 73 \% \\
\text { of national primary cases } \\
\text { included. }\end{array}$ & $\begin{array}{l}66,311 \text { primary cases } \\
\text { ( } 36,388 \text { aged } 0-19 \mathrm{y}) \text { and } \\
213,576 \mathrm{HH} \text { contacts } \\
\text { (148,724 aged } 0-19 \mathrm{y}) .89 \% \\
\text { of HH contacts tested }\end{array}$ & $<20 y$ & $\begin{array}{l}\text { RT-PCR (swab site not } \\
\text { stated) }\end{array}$ & $\begin{array}{l}\text { SAR from primary aged } 0-5 \mathrm{y} \\
22 \%(3313 / 14,306), 5-10 \mathrm{y} \\
39 \%(5960 / 15,263), 10-15 \mathrm{y} \\
43 \%(8908 / 20,596) 15-20 \mathrm{y} 51 \% \\
(12,440 / 24,197) \text { compared with } \\
52.3 \%(72,761 / 139,177) \text { aged } 20 \mathrm{y} \\
\text { plus. Adjusted OR for } \\
\text { transmission from index aged } \\
0-5 \mathrm{y} 1.11(1.03,1.19), 5-10 \mathrm{y} \\
0.95(0.90,1.0), 10-15 \mathrm{y} \\
0.82(0.78,0.85), 15-20 \mathrm{y} \\
0.70(0.67,0.72) \text { compared with } \\
30-35 y 0 . \\
\quad \text { (continued on next page) }\end{array}$ & 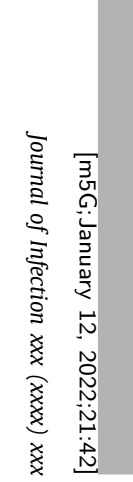 \\
\hline
\end{tabular}


Table 1 (continued)

\begin{tabular}{|c|c|c|c|c|c|c|c|c|c|c|c|c|}
\hline Authors & Source & Site & Dates & Virus/ variant & $\begin{array}{l}\text { Case } \\
\text { identification }\end{array}$ & Study type & Setting and exposure & $\mathrm{N}$ & $\begin{array}{l}\text { Age of } \\
\text { CYP }\end{array}$ & Testing & Findings & 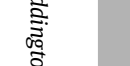 \\
\hline Telle et al. & $\begin{array}{l}\text { medRxiv then } \\
\text { published }\end{array}$ & Norway & $\begin{array}{l}1 \text { March } \\
2020-1 \text { Jan } \\
2021\end{array}$ & NS & $\begin{array}{l}\text { Infection/ } \\
\text { Population }\end{array}$ & Contact-tracing & $\begin{array}{l}\text { Norwegian Population } \\
\text { Registry linked with all } \\
\text { national COVIII testing } \\
\text { databases including test } \\
\text { and trace. Included all } \mathrm{HH} \\
\text { with children }<20 \mathrm{y} \text { and a } \\
\text { single identifiable index } \\
\text { case. } 3 \text { million of the } \\
\text { Norwegian population of } \\
5.4 \text { million were tested } \\
\text { during study period. }\end{array}$ & $\begin{array}{l}7548 \text { single index cases } \\
(1498<=16 y ; 200<7 y, 517 \\
7-12 y, 781 \text { 13-16y) and } \\
\text { their HH, including 26,991 } \\
\text { individuals (14,808 <20y } \\
\text { and 12,184 adults). Testing } \\
\text { of contacts within 14D } \\
\text { varied with index age: } 92 \% \\
0-6 y, 88 \% \text { 7-12y, 87\% } \\
\text { 13-16y and 60-70\% for } 17 \\
\text { plus. }\end{array}$ & $\begin{array}{l}0-16 y \\
(17-19 y \\
\text { not } \\
\text { reported } \\
\text { as } \\
\text { contact } \\
\text { testing } \\
<85 \%)\end{array}$ & $\begin{array}{l}\text { RT-PCR (swab site not } \\
\text { stated) of all contacts } \\
\text { regardless of symptoms } \\
\text { (after April 2020) }\end{array}$ & $\begin{array}{l}\text { SAR within } 14 \text { d: SAR was } \\
\text { highest from } 0 \text { to } 6 y \text { and from } \\
\text { parents to both children and } \\
\text { adults. SAR from children: index } \\
0-6 y \text { - } 23 \%(18,30) \text { to children and } \\
29 \%(24-34) \text { to parents; index } \\
7-12 y \text { y } 12 \%(10,15) \text { to children } \\
\text { and } 21 \%(19,24) \text { to parents; } \\
\text { index } 13-16 y 15 \%(13,18) \text { to } \\
\text { children and } 18 \%(16,21) \text { to } \\
\text { parents. SAR from parents: } \\
24 \%(23,25) \text { to children and } \\
38 \%(36,40) \text { to other parents. }\end{array}$ & $\begin{array}{l}3 \\
0 \\
3 \\
3 \\
0 \\
0 \\
0 \\
0 \\
0 \\
0\end{array}$ \\
\hline Hoehl et al. & $\begin{array}{l}\text { Handsearch for } \\
\text { R1; medRxiv } \\
\text { (Shenk et al.) } \\
\text { for R2\&3 }\end{array}$ & Germany & $\begin{array}{l}\text { R1: } 18 \text { Jun-10 } \\
\text { Sep } 2020 \\
\text { R2: } 18 \text { Jan-Feb } \\
112021 \\
\text { R3: } 17 \\
\text { May-June } 11 \\
\text { 2021, }\end{array}$ & $\begin{array}{l}\text { R1: NS } \\
\text { R2: WT } \\
\text { dominant, } \\
\text { alpha } \\
\text { emerging } \\
\text { R3: alpha } \\
\text { dominant }\end{array}$ & Population & Surveillance & $\begin{array}{l}\text { SAFE KiDS study Rounds } \\
1 \text {-3. Representative sample } \\
\text { of } 50 \text { daycare centres (R1), } \\
47 \text { centres (R2) and } 46 \\
\text { centres (R3) in state of } \\
\text { Hesse (1\% of facilities in } \\
\text { Hesse). } 30 \text { individuals } \\
\text { (children and staff) per } \\
\text { facility invited for weekly } \\
\text { home testing. R1 was low } \\
\text { community incidence with } \\
\text { wild type virus; R2 was } \\
\text { high incidence, R3 was } \\
\text { moderate incidence }\end{array}$ & $\begin{array}{l}\text { R1: } 1235 \text { participants from } \\
50 \text { centres ( } 859 \text { children; } \\
376 \text { staff). Total of } 13,273 \\
\text { swabs tested ( } 56 \% \text { oral). } \\
\text { Median } 6 \text { samples per child } \\
\text { and } 7 \text { per staff member. } \\
\text { R2: } 47 \text { centres with } 577 \\
\text { children and } 334 \text { staff } \\
\text { providing } 1 \text { or more swabs. } \\
\text { R3: } 46 \text { centres with } 756 \\
\text { children and } 226 \text { staff } \\
\text { providing } 1 \text { or more swabs }\end{array}$ & $\begin{array}{l}3 \\
\text { months } \\
\text { to } 8 y\end{array}$ & $\begin{array}{l}\text { RT-PCR weekly (buccal and } \\
\text { anal swabs from each } \\
\text { participant weekly). Buccal } \\
\text { only R3. Only buccal data } \\
\text { included here }\end{array}$ & $\begin{array}{l}\text { R1: } 2 \text { positive from } 2 \text { staff } \\
\text { members }(2 / 376) \text {. No positive } \\
\text { swabs from children }(0 / 9057 \\
\text { swabs in } 859 \text { children). } \\
\text { R2: } 2 \text { positive in children } \\
\text { (2/577) and } 0 \text { staff }(0 / 334) \text {. All } \\
\text { S-gene positive i.e. unlikely to } \\
\text { be alpha variant } \\
\text { R3: } 0 \text { children or staff positive }\end{array}$ & 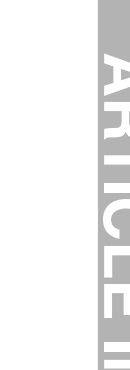 \\
\hline Kriemler et al & $\begin{array}{l}\text { medRxiv then } \\
\text { published }\end{array}$ & Switzerland & 1-11 Dec 2020 & NS & Population & Surveillance & $\begin{array}{l}14 \text { invited primary and } \\
\text { secondary schools from } \\
\text { high prevalence areas of } \\
\text { Zurich: a subset of the } 55 \\
\text { schools participating in } \\
\text { Ulyte et al. }\end{array}$ & $\begin{array}{l}641 / 1299(49 \%) \text { of invited } \\
\text { children participated, from } \\
67 \text { classes }\end{array}$ & $6-16 y$ & $\begin{array}{l}\text { RT-PCR oral swab: } \\
\text { participants tested twice } 1 \\
\text { week apart. }\end{array}$ & $\begin{array}{l}\text { positive RT-PCR in } 1 \\
\text { child }=0.2 \%(0,1.1) \text {; no evidence } \\
\text { of clustering in classes }\end{array}$ & \\
\hline Theuring et al. & medRxiv & Germany & 2-16 Nov 2020 & NS & Population & Surveillance & $\begin{array}{l}24 \text { randomly selected } \\
\text { schools in Berlin as per } \\
\text { Hommes et al. } 1 \text { class from } \\
\text { each school and their HH } \\
\text { members. FFF teaching till } \\
16 \text { Dec }\end{array}$ & $\begin{array}{l}N=1119 \text { ( } 352 \text { students } \\
\text { (177 primary, } 175 \\
\text { secondary), } 142 \text { staff and } \\
625 \text { HH members). Mean } \\
65 \% \text { eligible children } \\
\text { participated }\end{array}$ & $8-18 y$ & $\begin{array}{l}\text { RT-PCR - oral and NP } \\
\text { combined swabs- on all } \\
\text { participants (98.6\% } \\
\text { students, } 100 \% \text { staff and } \\
99.5 \% \text { HH). Serology on } \\
\text { dried blood spots. } \\
\text { Participants in } 8 \text { classes } \\
\text { with positive cases were } \\
\text { retested after } 1 \text { week. }\end{array}$ & $\begin{array}{l}\text { Prevalence: } 2.7 \%(1.2,5.0) \text { in } \\
\text { students }(6 / 177 \text { primary, } 3 / 175 \\
\text { secondary) and } 0.7 \%(0.0,3.9) \text { in } \\
\text { staff }(1 / 142) ; 8 / 24 \text { classes had } 1 \\
\text { or } 2 \text { cases, with none }>2 . \mathrm{HH} \\
\text { prevalence: } 2.3(1.3,3.8)=14 \\
\text { cases in } 9 \mathrm{HH} .3 / 9 \mathrm{HH} \text { had } \\
\text { positive students in the study } \\
\text { but origin of infection unclear. } \\
\text { Seropositivity in } 2.0 \%(0.8,4.1) \\
\text { students and } 1.4 \%(0.6,2.7) \text { of } \\
\text { staff; } 8 \text { classes with a positive } \\
\text { test were retested after } 1 \text { week } \\
\text { (after variable quarantine): } 1 \\
\text { student and } 1 \text { staff were } \\
\text { positive but judged not to be } \\
\text { school related. }\end{array}$ & $\stackrel{\bar{\Xi}}{\overline{3}}$ \\
\hline Thielecke et al. & $\begin{array}{l}\text { medRxiv then } \\
\text { published }\end{array}$ & Germany & $\begin{array}{l}28 \mathrm{Sep}-2 \text { Oct } \\
2020\end{array}$ & NS & Population & Surveillance & $\begin{array}{l}12 \text { randomly selected } \\
\text { kindergartens from }>2700 \\
\text { in Berlin. FTF }\end{array}$ & $\begin{array}{l}N=720: 155 \text { children, } 78 \\
\text { staff, } 487 \mathrm{HH} \text { members.\% of } \\
\text { eligible participating not } \\
\text { stated. }\end{array}$ & $1-6 y$ & $\begin{array}{l}\text { RT-PCR (combined oral and } \\
\text { NP swabs) and serology } \\
\text { IgG on dried blood spots }\end{array}$ & $\begin{array}{l}\text { None of } 701 \text { PCR samples was } \\
\text { positive; no children, nil HH } \\
\text { and } 1 \text { staff were seropositive . } \\
\text { (continued on next page) }\end{array}$ & 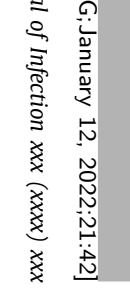 \\
\hline
\end{tabular}


Table 1 (continued)

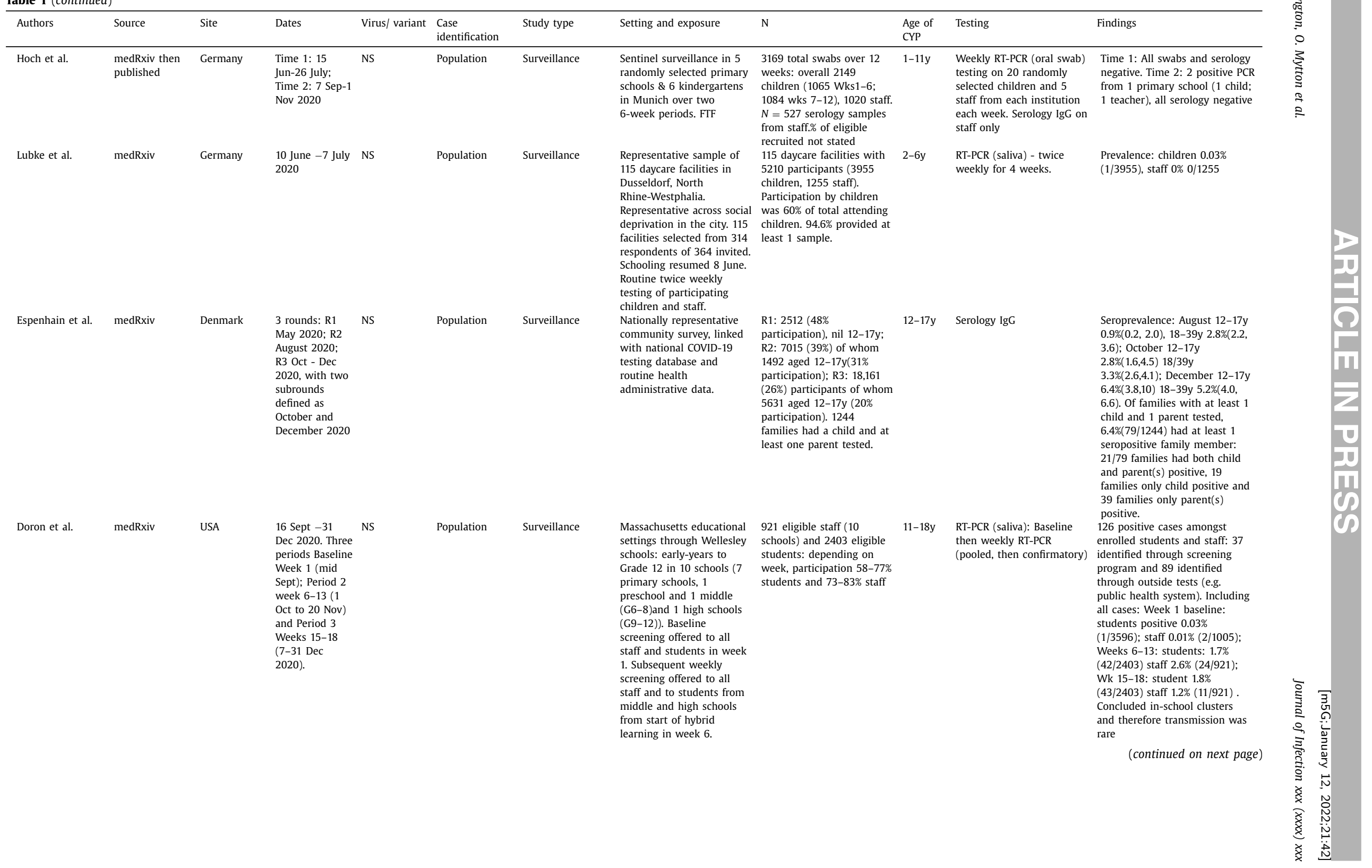


Table 1 (continued)

\begin{tabular}{|c|c|c|c|c|c|c|c|c|c|c|c|}
\hline Authors & Source & Site & Dates & Virus/ variant & $\begin{array}{l}\text { Case } \\
\text { identification }\end{array}$ & Study type & Setting and exposure & $\mathrm{N}$ & $\begin{array}{l}\text { Age of } \\
\text { CYP }\end{array}$ & Testing & Findings \\
\hline ONS SIS & Professional & UK & $\begin{array}{l}\text { Round 1: 3-19 } \\
\text { Nov 2020; } \\
\text { Round 2: 2-10 } \\
\text { Dec 2020; } \\
\text { (Round 3 not } \\
\text { undertaken due } \\
\text { to school } \\
\text { closures) Round } \\
\text { 4: 15-31 March } \\
\text { 2021; Round 5: } \\
\text { 5-21 May 2021 }\end{array}$ & $\begin{array}{l}\text { R1: NS } \\
\text { R2: alpha } \\
\text { emerging } \\
\text { R4: alpha } \\
\text { dominant } \\
\text { R5: delta } \\
\text { dominant by } \\
\text { late May }\end{array}$ & Population & Surveillance & $\begin{array}{l}\text { Oversampling of schools in } \\
\text { high prevalence areas of } \\
\text { England. }\end{array}$ & $\begin{array}{l}\text { Round 1: } 105 \text { schools ( } 63 \\
\text { secondary, } 42 \text { primary) in } \\
14 \text { local authorities ( (64\% } \\
\text { high prevalence, } 36 \% \text { low } \\
\text { prevalence); } n=9662 \\
\text { (students: primary } 2137 \\
\text { secondary } 3099 \text {; staff } \\
\text { primary } 1068 \text { secondary } \\
3054 \text { ) - participation } 17 \% \\
\text { students } 51 \% \text { staff. Round } \\
2: 121 \text { schools (41 primary, } \\
80 \text { secondary) in } 15 \text { local } \\
\text { authorities: } n=5114 \text { staff, } \\
7089 \text { pupils. Participation } \\
15 \% \text { students } 40 \% \text { staff. } \\
\text { Note: } 7751 \text { ( } 4429 \text { students } \\
3322 \text { staff) participated in } \\
\text { both rounds. Round } 4: 137 \\
\text { schools in } 15 \text { local } \\
\text { authorities: data reported } \\
\text { on } 7156 \text { secondary } \\
\text { students and } 2645 \text { staff } \\
\text { (17\% of eligible students; } \\
29 \% \text { staff). Round } 5: 57 \\
\text { primary and } 85 \text { secondary } \\
\text { schools: } 4207 \text { primary and } \\
8297 \text { secondary students \& } \\
1348 \text { primary and } 2637 \\
\text { secondary staff (estimated } \\
\text { response rate } 25 \% \text { primary } \\
\& 17 \% \text { secondary students) }\end{array}$ & $4-19 y$ & $\begin{array}{l}\text { RT-PCR (NP swab); serology } \\
\text { IgG on all participating } \\
\text { students and staff in } \\
\text { participating schools }\end{array}$ & 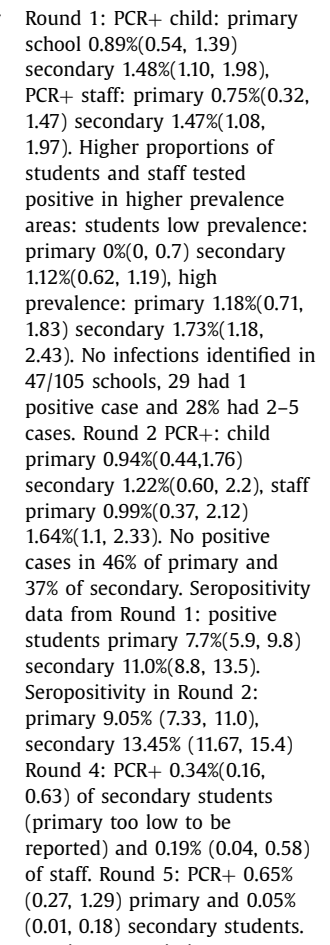 \\
\hline House et al. & Professional & UK & $\begin{array}{l}26 \text { Apr 2020-15 } \\
\text { Feb2021 R1: } 26 \\
\text { Ap-1 Sep 2020:; } \\
\text { R2: 1 Sep-15 } \\
\text { Nov 2020; R3: } \\
\text { 15 Nov 2020-1 } \\
\text { Jan 2021; R4: } 1 \\
\text { Jan-15 Feb 2021 }\end{array}$ & $\begin{array}{l}\text { R1: WT } \\
\text { R2: WT } \\
\text { R3: alpha } \\
\text { emerging } \\
\text { R4: alpha } \\
\text { dominant }\end{array}$ & Population & Surveillance & $\begin{array}{l}\text { National longitudinal HH } \\
\text { population surveillance } \\
\text { study (ONS COVID-19 } \\
\text { Infection Survey): weekly } \\
\text { testing of a nationally } \\
\text { representative set of } \\
\text { households in England. } \\
\text { Analyses limited to HH <7 } \\
\text { persons. } \\
\text { R1: schools closed, low } \\
\text { prevalence } \\
\text { R2: high prevalence, } \\
\text { schools open } \\
\text { R3: high prevalence, } \\
\text { schools mainly open } \\
\text { R4: schools closed, high } \\
\text { prevalence }\end{array}$ & 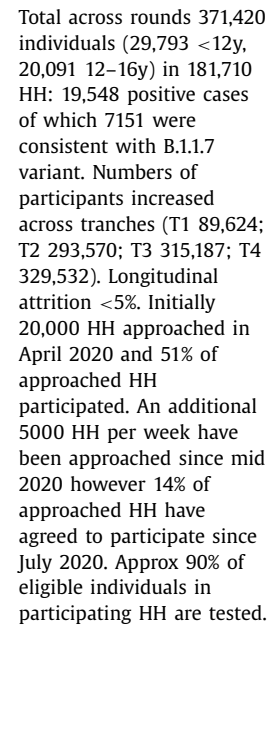 & $2-16 y$ & $\begin{array}{l}\text { RT-PCR weekly (NP and } \\
\text { oral swab) }\end{array}$ & $\begin{array}{l}\text { Bayesian transmission } \\
\text { probability models estimated } \\
\text { susceptible-infectious } \\
\text { transmission probabilities } \\
\text { including infectivity and } \\
\text { external force of infection by } \\
\text { age, based upon first case } \\
\text { within each HH. Found relative } \\
\text { transmissibility not significantly } \\
\text { different to adults for 2-11y for } \\
\text { each tranche, with 12-16y } \\
\text { having significantly lower } \\
\text { transmissibility in T3 (RR } 0.7 \text { ) } \\
\text { but not in other tranches. The } \\
\text { relative external exposure } \\
\text { compared with adults was } \\
\text { significantly higher for 2-11y } \\
\text { for T3 (RR 1.4) and for 12-16y } \\
\text { for T2 and T3 (RR 1.64 and 2.35 } \\
\text { respectively). }\end{array}$ \\
\hline
\end{tabular}


Table 1 (continued)

\begin{tabular}{|c|c|c|c|c|c|c|c|c|c|c|c|}
\hline Authors & Source & Site & Dates & Virus/ variant & $\begin{array}{l}\text { Case } \\
\text { identification }\end{array}$ & Study type & Setting and exposure & $\mathrm{N}$ & $\begin{array}{l}\text { Age of } \\
\text { CYP }\end{array}$ & Testing & Findings \\
\hline Villani et al & PubMed & Italy & $\begin{array}{l}21 \text { Sep-4 Dec } \\
2020 \text {, in } 3 \\
\text { periods: } 21 \\
\text { Sep-12 Oct; } 19 \\
\text { Oct-13 Nov; } 16 \\
\text { Nov-4 Dec }\end{array}$ & NS & Population & Surveillance & $\begin{array}{l}\text { Schools: } 2 \text { K12 schools in } \\
\text { Rome }\end{array}$ & $\begin{array}{l}1083 \text { students and } 168 \\
\text { staff: } 96.5-100 \% \text { student } \\
\text { participation by age }\end{array}$ & $3-18 y$ & $\begin{array}{l}\text { RT-PCR: oral swabs: } 3 \\
\text { monthly samples all } \\
\text { participants }\end{array}$ & $\begin{array}{l}13 \text { positive students \& } 3 \text { staff } \\
\text { across } 3 \text { rounds (3431 samples). } \\
\text { Positive Round } 1: 1 / 1099, \\
\text { Round 2: } 12 / 1075 ; \text { Round } 3 \text { : } \\
3 / 1257 \text {. Using the participant } N \\
\text { of students as swab number for } \\
\text { each round, prevalence in } \\
\text { children was R1: } 1 / 1083 \text {, R2: } \\
\text { 9/1083 and R3: } 3 / 1083 \text { (swab } \\
\text { numbers for students not } \\
\text { given). Only } 2 \text { classrooms had } \\
>=1 \text { positive ( } 2 \text { students; } 1 \\
\text { with student and staff } \\
\text { member). Note } 2+\text { students } \\
\text { were siblings. Prevalence of } 0.1 \text {, } \\
1.1 \text { and } 0.2 \% \text { was lower than } \\
\text { background for age }\end{array}$ \\
\hline Hommes et al. & $\begin{array}{l}\text { medRxiv then } \\
\text { published }\end{array}$ & Germany & 11-19 Jun 2020 & NS & Population & Surveillance & $\begin{array}{l}24 \text { randomly selected } \\
\text { schools in Berlin; FTF } \\
\text { teaching reopened } 28 \text { April } \\
\text { but } 15 \% \text { of teaching virtual } \\
\text { in primary and } 50 \% \text { in } \\
\text { secondaries. }\end{array}$ & $\begin{array}{l}n=535: 192 \text { primary and } \\
192 \text { secondary students } \\
\text { and } 150 \text { school staff.65\% of } \\
\text { students participated }\end{array}$ & $8-18 y$ & $\begin{array}{l}\text { RT-PCR- oral and NP } \\
\text { combined swabs- plus } \\
\text { dried blood spot serology } \\
\text { on all participants }\end{array}$ & $\begin{array}{l}1 \text { positive case identified in } \\
\text { 16yo: prevalence } 0.5 \% \text { for } \\
\text { secondary and no teachers. } \\
\text { Positive IgG in } 7 \text { students (1.8\%) } \\
\text { and no teachers: } 3 \text { clustered in } \\
\text { one secondary class. }\end{array}$ \\
\hline Kirsten et al. & $\begin{array}{l}\text { medRxiv (as } \\
\text { Armann et al.) } \\
\text { then published } \\
\text { as Kirsten et al. }\end{array}$ & Germany & $\begin{array}{l}\text { Time } 125 \\
\text { May-30 June } \\
\text { 2020; Time 2: } \\
\text { 15 Sep-13 Oct } \\
2020\end{array}$ & NS & Population & Surveillance & $\begin{array}{l}13 \text { secondary schools in } \\
\text { eastern Saxony. School } \\
\text { recruitment not stated. } \\
\text { Schools reopened FTF } 18 \\
\text { May and then late August } \\
\text { after summer break }\end{array}$ & $\begin{array}{l}\text { T1: } 1538 \text { students ( } 76 \% \\
\text { participation) \& } 507 \\
\text { teachers; T2: } 1334 \text { students } \\
\text { (87\% of T1) \& } 445 \text { teachers }\end{array}$ & $12-19 y$ & Serology IgG & $\begin{array}{l}\text { Seroprevalence T1: } 12 \text { positive } \\
\text { (11 students, } 1 \text { teacher) }=0.6 \% \text {; } \\
\text { T2: } 12 \text { positive }(11 \text { students, } 1 \\
\text { teacher). Positives in } 7 / 13 \\
\text { schools, with maximum of } 4 \text { in } \\
\text { any school. }\end{array}$ \\
\hline Ulyte et al. & $\begin{array}{l}\text { R1 \& 2: } \\
\text { medrxiv then } \\
\text { published } \\
\text { R3: medrxiv }\end{array}$ & Switzerland & $\begin{array}{l}\text { R1: } 16 \text { Jun-9 } \\
\text { July } 2020 \\
\text { R2: } 26 \text { Oct-19 } \\
\text { Nov } 2020 \\
\text { R3: } 15 \text { Mar - } 16 \\
\text { April } 2021\end{array}$ & $\begin{array}{l}\text { R1 \& 2: NS } \\
\text { R3: alpha } \\
\text { dominant }\end{array}$ & Population & Surveillance & $\begin{array}{l}\text { Ciao Corona study ( } 3 \\
\text { rounds): Primary and } \\
\text { secondary schools in } \\
\text { Zurich; } 55 \text { randomly } \\
\text { selected schools ( } 55 / 156 \\
\text { invited), } 275 \text { classes; FTF } \\
\text { learning at all rounds }\end{array}$ & $\begin{array}{l}\text { R1 } n=2603 ; \text { R2 } n=2552 . \\
\text { R3: } n=2487 \text {, including } \\
\text { 250 newly enrolled } \\
\text { children. Retention was } \\
\text { 84\% from R1-R2 and 88\% } \\
\text { from R2-R3. }\end{array}$ & $6-16 y$ & Serology IgG & $\begin{array}{l}\text { R1 seropositive }=74 / 2496 . \text { R2 } \\
\text { seropositive }=173 / 2503 . \\
\text { Modelled seroprevalence R1 } \\
2.4 \%(1.4,3.6) ; \mathrm{R} 2 \text { new } \\
\text { seropositive } 4.5 \%(3.2,6.0) ; \\
\text { positive } \mathrm{R} 1 \& 27.8 \%(6.2,9.5) \text {. No } \\
\text { clear age differences across } \\
\text { schools. Clustering of }>=3 \text { cases } \\
\text { slightly higher than expected } \\
\text { from chance } \\
\text { R3: Raw data: } 447 \text { positive out } \\
\text { of } 2483 \text { tests: modelled } \\
\text { seroprevalence } 16.4 \% \text { (12.1, } \\
\text { 19.5). Clustering of }>=3 \text { cases } \\
\text { slightly higher than expected } \\
\text { from chance }\end{array}$ \\
\hline
\end{tabular}

(continued on next page) 
Table 1 (continued)

\begin{tabular}{|c|c|c|c|c|c|c|c|c|c|c|c|}
\hline Authors & Source & Site & Dates & Virus/ variant & $\begin{array}{l}\text { Case } \\
\text { identification }\end{array}$ & Study type & Setting and exposure & $\mathrm{N}$ & $\begin{array}{l}\text { Age of } \\
\text { CYP }\end{array}$ & Testing & Findings \\
\hline Willeit et al. & $\begin{array}{l}\text { medRxiv then } \\
\text { published }\end{array}$ & Austria & $\begin{array}{l}\text { Time 1: } 28 \\
\text { Sep-22 Oct } \\
\text { 2020; Time 2: } \\
\text { 10-16 Nov 2020 }\end{array}$ & NS & Population & Surveillance & $\begin{array}{l}\text { Random sample of } 6 \% \text { of all } \\
\text { Austrian primary \& } \\
\text { secondary schools }=250 \text {. } \\
60 \text { students per school } \\
\text { invited (across all classes). } \\
\text { Random sample of } \\
\text { teachers. Fully FTF. Note } \\
\text { schools closed } 16 \text { Nov due } \\
\text { to national lockdown }\end{array}$ & $\begin{array}{l}\text { T1: } 10,156 \text { samples from } \\
243 \text { schools participating } \\
\text { (97.2\% of schools; no data } \\
\text { on\% children participating) } \\
n=8934 \text { students \& } 1222 \\
\text { teachers; } 72: 3745 \text { samples } \\
\text { from } 88 \text { schools (reduced } \\
\text { due to lockdown). Median } \\
40 \text { children and } 6 \text { teachers } \\
\text { per school. } N=3295 \\
\text { students \& } 450 \text { teachers }\end{array}$ & $6-16 y$ & RT-PCR (gargle specimens) & $\begin{array}{l}\text { T1: prevalence students } \\
0.4 \%(0.3,0.5) \text { teachers } 0.6 \%(0.3, \\
1.3) ; 0 \text { cases in } 209 / 243 \text { schools, } \\
1 \text { in } 28 \text { schools and } 2 \text { in } 6 \\
\text { schools. T2: children } 1.5 \%(1.1, \\
2.0) \text { teachers } 0.4 \%(0.1,1.8) .0 \\
\text { cases in } 52 / 88 \text { schools, } 1 \text { in } 23, \\
2 \text { in } 10 \text { and } 3 \text { cases in } 4 \text { schools. } \\
\text { No significant difference in } \\
\text { prevalence in primary versus } \\
\text { secondary. in regression } \\
\text { analyses, social deprivation and } \\
\text { community prevalence } \\
\text { predicted school prevalence. } \\
100 \% \text { increase in community } \\
\text { prevalence increased odds of } \\
\text { school prevalence by } 66 \% \text { (OR } \\
1.66(1.39,1.99)\end{array}$ \\
\hline $\begin{array}{l}\text { Ladhani et al. } \\
\text { sKIDSs }\end{array}$ & Professional & UK & $\begin{array}{l}\text { June-Dec 2020: } \\
\text { RT-PCR } \\
\text { June-July. } \\
\text { Serology round } \\
1 \text { June, round } 2 \\
\text { July, round } 3 \\
\text { Nov-Dec 2020; }\end{array}$ & $\begin{array}{l}\text { R1: WT } \\
\text { R2: WT } \\
\text { dominant, } \\
\text { alpha } \\
\text { emerging }\end{array}$ & Population & Surveillance & $\begin{array}{l}\text { English primary schools } \\
\text { (across all regions) and } \\
\text { early years settings after } \\
\text { reopening of schools June } \\
2020 \text { (SKIDS study (Rounds } \\
1 \& \text { 2)). Schools all FTF. } \\
\text { Note alpha variant } \\
\text { predominant for Round } 4 .\end{array}$ & $\begin{array}{l}\text { RT-PCR: Round 1: } 11966 \\
\text { participants (6727 students, } \\
4628 \text { staff, and } 611 \text { with } \\
\text { unknown staff or student } \\
\text { status) in } 131 \text { schools had } \\
40501 \text { swabs taken: . } \\
\text { Serology: } 45 \text { schools } 816 \\
\text { students, } 209 \text { staff) } \\
\text { recruited. } 95 \% \text { participant } \\
\text { recruitment. }\end{array}$ & $4-12 y$ & $\begin{array}{l}\text { RT-PCR (NP swab) and } \\
\text { Serology IgG }\end{array}$ & $\begin{array}{l}\text { Round 1: RT-PCR: } 1 \text { student and } \\
5 \text { staff positive during } 4 \text { weeks: } \\
\text { estimated incidence rate/wk } \\
\text { student } 4 \cdot 1(0 \cdot 1-22 \cdot 8) \text {, staff: } \\
12 \cdot 5(1 \cdot 5-45 \cdot 0) \text { per } 100000 \text {. } \\
\text { Seropositive: Round } 1: \text { children } \\
11 \cdot 2 \%(7 \cdot 9,15 \cdot 1) \text { staff } \\
15.2 \%(11.9,18.9) \text {. Seropositivity } \\
\text { was not clustered (in model } \\
\text { after adjustment) by school for } \\
\text { children but was for staff. } \\
\text { Seropositivity was not } \\
\text { associated with school } \\
\text { attendance during lockdown } \\
\text { (children or staff). Round } 2: 74 \% \\
\text { participation: children } 10.4 \% \\
\text { staff } 13.1 \% \text { - only } 5 \\
\text { seroconversions (staff \& } \\
\text { children) between rounds. } \\
\text { Round } 3: 54.2 \% \text { participation for } \\
\text { children: } 8.6 \% \text { of children and } \\
11.2 \% \text { of staff. }\end{array}$ \\
\hline Jordan et al. & Professional & Spain & $\begin{array}{l}\text { 29- Jun - } 31 \\
\text { July } 2020\end{array}$ & NS & Population & $\begin{array}{l}\text { Surveillance } \\
\text { (prospective) with } \\
\text { contact-tracing }\end{array}$ & $\begin{array}{l}\text { Children and staff in } 22 \\
\text { summer schools in } \\
\text { Barcelona over 2-5 weeks. } \\
\text { Attended } 40 \mathrm{~h} / \text { week. Note } \\
\text { additional data on children } \\
\text { identified through } \\
\text { symptom-based screening } \\
\text { (Recruitment Pathway 2) } \\
\text { not included here. }\end{array}$ & $\begin{array}{l}5240 \text { samples from } 1905 \\
\text { participants in } 22 \text { camps } \\
\text { (45\% of recruited camps) } \\
1509 \text { children and } 396 \\
\text { adults; } 9 \text { child and } 3 \text { adult } \\
\text { primary cases identified } \\
\text { through screening. } 89 \text { close } \\
\text { contacts of the } 9 \text { child } \\
\text { cases identified and tested. } \\
90 \% \text { of contacts } \\
\text { participated. }\end{array}$ & $3-15 y$ & $\begin{array}{l}\text { RT-PCR saliva samples. } \\
\text { Prospective weekly testing } \\
\text { of all children; contacts } \\
\text { tested at } 0,7,14 \text { days. nd } \\
\text { serology IgG: all children at } \\
\text { time } 0 \text {; contacts at } 0 \text { and } 5 \\
\text { weeks. }\end{array}$ & $\begin{array}{l}\text { PCR+: } 12 / 5240 \text { over } 5 \text { weeks } \\
\text { (5/580 nasopharyngeal } \\
\text { validation tests were positive): } \\
\text { 9/1509 children }=0.6 \% \text {. SRR } \\
\text { from } 9 \text { child index }=1.1 \% \\
\text { (1/89). SAR from adult index } \\
\text { was } 1.6 \% \text { ( } 1 / 63)\end{array}$ \\
\hline
\end{tabular}

(continued on next page) 
Table 1 (continued)

\begin{tabular}{|c|c|c|c|c|c|c|c|c|c|c|c|}
\hline Authors & Source & Site & Dates & Virus/ variant & $\begin{array}{l}\text { Case } \\
\text { identification }\end{array}$ & Study type & Setting and exposure & $\mathrm{N}$ & $\begin{array}{l}\text { Age of } \\
\text { CYP }\end{array}$ & Testing & Findings \\
\hline Fontanet et al. & $\begin{array}{l}\text { medRxiv then } \\
\text { published }\end{array}$ & France & $\begin{array}{l}28-30 \text { April } \\
2020\end{array}$ & NS & Population & Surveillance & $\begin{array}{l}6 \text { French primary schools } \\
\text { in a city that had } \\
\text { previously experienced an } \\
\text { outbreak in the local } \\
\text { high-school. Data included } \\
\text { here from the primary } \\
\text { schools; the single high } \\
\text { school data not included as } \\
\text { this was a single institution } \\
\text { outbreak and data were } \\
\text { not population-based }\end{array}$ & $\begin{array}{l}510 \text { children (49\% of } \\
\text { eligible/invited) and } 42 \\
\text { teachers (82\% of invited) } \\
\text { provided sammles. Also } 641 \\
\text { parents of children and } 119 \\
\text { other HH members } \\
\text { provided samples. }\end{array}$ & $6-11 \mathrm{y}$ & Serology IgG & $\begin{array}{l}\text { Seropositivity in } 8.8 \%(45 / 510) \text { of } \\
\text { primary school children, } \\
7.1(3 / 42) \% \text { of teachers, } \\
11.9 \%(76 / 641) \text { of parents and } \\
11.8 \%(14 / 119) \text { other } \mathrm{HH} \\
\text { members. Seroprevalence did } \\
\text { not vary significantly by age. } \\
\text { Note } 61 \% \text { of parents of an } \\
\text { infected pupil were seropositive } \\
\text { compared with } 6.9 \% \text { of parents } \\
\text { of non-infected parents), } \\
\text { suggesting transmission } \\
\text { occurred primarily within } \\
\text { households. } 44 \% \text { of seropositive } \\
\text { children < } 12 y \text { were } \\
\text { asymptomatic. }\end{array}$ \\
\hline $\begin{array}{l}\text { Ladhani et al. } \\
\text { sKIDSsPLUS }\end{array}$ & medRxiv & UK & $\begin{array}{l}\text { R1: } 22 \text { Sep-17 } \\
\text { Oct 2020 } \\
\text { R2: } 3-17 \text { Dec } \\
\text { 2020 } \\
\text { R3: } 23 \text { Mar-21 } \\
\text { April 2021 }\end{array}$ & $\begin{array}{l}\text { R1: WT } \\
\text { R2: WT } \\
\text { dominant, } \\
\text { alpha } \\
\text { emerging } \\
\text { R3: alpha } \\
\text { dominant, } \\
\text { delta } \\
\text { emerging }\end{array}$ & Population & Surveillance & $\begin{array}{l}\text { sKIDsPLUS study of } 18 \\
\text { secondary schools } \\
\text { purposively recruited } \\
\text { across England, aligned } \\
\text { with sKIDs study of } \\
\text { primary schools also } \\
\text { included here. Round } 4 \text { - } \\
\text { undertaken immediately } \\
\text { after schools reopened } \\
\text { after lengthy lockdown (1 } \\
\text { Jan to } 7 \text { March 2021). } \\
\text { Schools all FTF. Note alpha } \\
\text { variant predominant for } \\
\text { Round } 4 \text {. }\end{array}$ & $\begin{array}{l}\text { R1: } 893 \text { students, } 861 \text { staff } \\
\text { R2: } 893 \text { students, } 873 \text { staff } \\
\text { R3: } 1094 \text { students and } 792 \\
\text { staff. }\end{array}$ & $11-18 y$ & $\begin{array}{l}\text { RT-PCR (NP swab) and } \\
\text { Serology IgG. Data provided } \\
\text { for various assays - the } \\
\text { Abbott assay data were } \\
\text { used consistently across } \\
\text { R1-3 and therefore used } \\
\text { here. }\end{array}$ & $\begin{array}{l}\text { PCR data only provided for } \\
\text { Round 3: Positive in } 0.18 \% \\
\text { (2/1094) children and 0/792 } \\
\text { staff. Clustering was not } \\
\text { significant }(p=0.1) \text { for school } \\
\text { infections in Round } 3 \text {. } \\
\text { Serology data provided for } \\
\text { Rounds 1-3: Serology data } \\
\text { provided for Rounds } 1-3: \text { R1: } \\
\text { seropositive student } 12.8 \% \\
\text { (114/893) staff } 9.2 \% \text { ( } 799861) \text {; } \\
\text { R2: } 13.1 \% \text { student }(117 / 893) \\
\text { 13.4\% staff (117/873); Round 3: } \\
\text { students 22.1\% (227/1029), staff } \\
\text { 19.5\% (150/771). }\end{array}$ \\
\hline Lachassinne et al. & Professional & France & $\begin{array}{l}4 \text { Jun-3 July } \\
2020\end{array}$ & NS & Population & Surveillance & $\begin{array}{l}\text { Early years setting: } \\
\text { recruited children and staff } \\
\text { who attended daycare } \\
\text { during national lockdown } \\
(15 \text { Mar-9 May } 2020) \text { as } \\
\text { parents were essential } \\
\text { workers; recruited from } 22 \\
\text { early years settings in Paris } \\
\text { region. All children invited } \\
\text { to participate and } \\
\text { recruitment ceased once } \\
\text { planned } N \text { achieved. Also } \\
\text { studied parental serology. }\end{array}$ & $\begin{array}{l}\text { Recruited the first } 327 \\
\text { children agreed to } \\
\text { participate, along with } 197 \\
\text { daycare staff i.e. } 100 \% \text { of } \\
\text { recruited were tested. }\end{array}$ & $0.5-4 y$ & $\begin{array}{l}\text { RT-PCR nasal swabs. Stool } \\
\text { samples also collected but } \\
\text { data not examined here. } \\
\text { Serology Ig \& IgM. }\end{array}$ & $\begin{array}{l}\text { Seropositivity in } 4.3 \% \text { ( } 14 / 327) \\
\text { children and } 17.7 \%(4 / 197) \text { staff. } \\
\text { The } 14 \text { seropositive children } \\
\text { came from } 13 \text { daycare centres - } \\
\text { i.e. no evidence of clustering of } \\
\text { infection. } 55 \%(6 / 11) \text { of } \\
\text { seropositive children had a } \\
\text { seropositive parent compared } \\
\text { with } 14 \% \text { ( } 22 / 149 \text { ) of } \\
\text { seronegative children. PCR - } \\
0 / 197 \text { nasal swabs were } \\
\text { positive. Found no evidence of } \\
\text { transmission within daycare } \\
\text { centres in this high risk group. } \\
\text { Concluded most children were } \\
\text { infected from household } \\
\text { contacts. }\end{array}$ \\
\hline
\end{tabular}

Oral $=$ oropharyngeal.

$\mathrm{NP}=$ nasopharyngeal

$R=$ Round.

Brackets () show 95\% CI.

Variant: NS = not stated; likely original or wild-type virus. VOC $=$ variant of concern. WT $=$ wild type (original) virus. 
Table 2

Moderators of prevalence and seroprevalence in school studies.

\begin{tabular}{lllll}
\hline Age & $\begin{array}{l}\text { PCR prevalence } \\
\text { Odds ratios }(95 \% \mathrm{CI})\end{array}$ & $\mathrm{p}$ & $\begin{array}{l}\text { Seroprevalence } \\
\text { Odds ratios }(95 \% \mathrm{CI})\end{array}$ & $\mathrm{p}$ \\
\hline 0-19 years (reference) & 1 & - & 1 & - \\
Early years $\leq 7$ years & $0.245(0.030,2.000)$ & 0.189 & - & - \\
Children 5-12 years & $0.649(0.207,2.034)$ & 0.458 & $1.567(0.228,10.773)$ & 0.648 \\
Adolescents 12-19 years & $1.433(0.429,4.787)$ & 0.559 & $1.185(0.178,7.877)$ & 0.860 \\
Community SARS-CoV-2 14 day incidence per 100,000 population (continuous) & & \\
Contemporary with study & $1.003(1.001,1.004)$ & $<0.001$ & $1.001(0.999,1.003)$ & 0.307 \\
Month previous to study & $1.003(1.001,1.006)$ & 0.008 & $1.005(1.000,1.007)$ & 0.038 \\
Two months previous to study & $1.001(0.997,1.005)$ & 0.591 & $1.005(1.002,1.008)$ & 0.003 \\
School attendance (\% in face-to-face learning) & $1.001(0.982,1.021)$ & 0.908 & $1.020(0.977,1.066)$ & 0.375 \\
PCR source & & & & - \\
Swab (nasopharyngeal or oropharyngeal) & 1 & & - & \\
Saliva or gargle & $1.54(0.49,4.84)$ & 0.456 & - & \\
\hline
\end{tabular}

were retrieved in full-text and reviewed independently by 2 researchers (RV and CW or OM) for eligibility and quality.

\section{Outcomes and data extraction}

Outcomes of interest were:

1. From contact-tracing studies: secondary attack rates (SAR) by age of index cases $(<18-20$ years compared adults) in contacttracing studies. SAR by age of contact, SAR from adult index cases and effect estimates for adjusted transmission models from CYP were also extracted where data allowed.

2. From population-based studies:

a. School studies: prevalence or seroprevalence of SARS-CoV2 infection and presence of clustering (frequency of occurrence of $>2$ cases) of infection within settings. We also extracted data on school attendance (see below under metaregression)

b. Longitudinal incidence studies: effect estimates for transmission models from CYP aged 0-19 years.

Data from each study were extracted to a spreadsheet and checked for accuracy by four reviewers (RV, JC, CW and JW). Source of data in each study are shown in Appendix Table 2. We approached authors for further data where necessary.

\section{Quality and bias evaluation}

Methodological quality was independently assessed by two authors (RV and CW) using a score adapted from previously published quality assessment tools ${ }^{23-26}$ for prevalence, cohort and case-control studies (see Appendix for details and Appendix Tables 3 and 4). Only studies of high and medium quality at low risk of bias were included in these analyses.

\section{Data synthesis and analysis}

Studies were included in random effects meta-analyses and meta-regressions using a multilevel framework. This accounted for many studies collecting multiple rounds of data collection over time or for studies providing data for CYP age-groups (e.g. primary or secondary students). Analyses used the metafor package in $\mathrm{R}$, using log-transformed proportions.

For contact-tracing studies, meta-analyses were undertaken of secondary attack rate (SAR) from index children grouped by setting, age of index child and age of contact. Meta-analysis comparing SAR from child index cases with SAR from adult index cases was undertaken first using raw SAR data and then using estimates of relative transmissibility from adjusted transmission models where data were provided.
For school population-based studies, we first undertook separate meta-analyses of studies providing prevalence and seroprevalence data grouped by age-group. We then used meta-regression to examine associations of school prevalence with:

1. Community 14-day incidence of SARS-CoV-2 across the study period and for the one and two months prior (see Appendix Table 5 for data and sources).

2. School attendance (\% face-to-face) in each study (Appendix Table 6). Attendance was measured at the measurement-round level as this varied within a study over time.

We also undertook a post-hoc analysis to examine whether the use of nasopharyngeal or oral swab compared with saliva or gargle sample influenced estimates.

\section{Role of the funding source}

No funding obtained for these analyses.

\section{Ethics}

Ethics permission not required for these secondary analyses of published data.

\section{Results}

The PRISMA flow diagram is shown in Fig. 1. Titles and abstracts of 4511 articles were reviewed from electronic databases. Two additional studies were identified through searching citation lists and 16 through professional networks. 336 were assessed in full-text and 89 articles were judged potentially eligible. 45 studies (46 articles) were excluded as being at critical risk of bias (see Appendix Table 7). Characteristics of the 37 included studies (described in 43 articles, some of which describe later rounds of a study) are shown in Table 1.

Sixteen studies were contact-tracing studies (6 school; ${ }^{27-33} 10$ household ${ }^{2,34-42}$ ), 2 provided both contact-tracing and population data (both school studies ${ }^{43,44}$ ) and 19 were population studies (17 in educational settings; ${ }^{9,10,45-59} 2$ were national community surveillance surveys ${ }^{60,61}$ ).

Twenty-four studies were high quality (13 population; 10 contact-tracing and 1 study providing both data) and 13 studies were medium quality ( 6 population, 6 contact-tracing and 1 study providing both data). Of the 43 articles reporting the 37 studies, 26 (60\%) were published, 11 (26\%) were preprints and 6 (14\%) were government or university reports.

Eight studies were from Germany, 4 from the UK, 3 from South Korea and the USA, 2 each from China, France, Switzerland, Denmark, Italy and Norway, one included data from both the Nether- 


\section{PRISMA 2009 Flow Diagram}

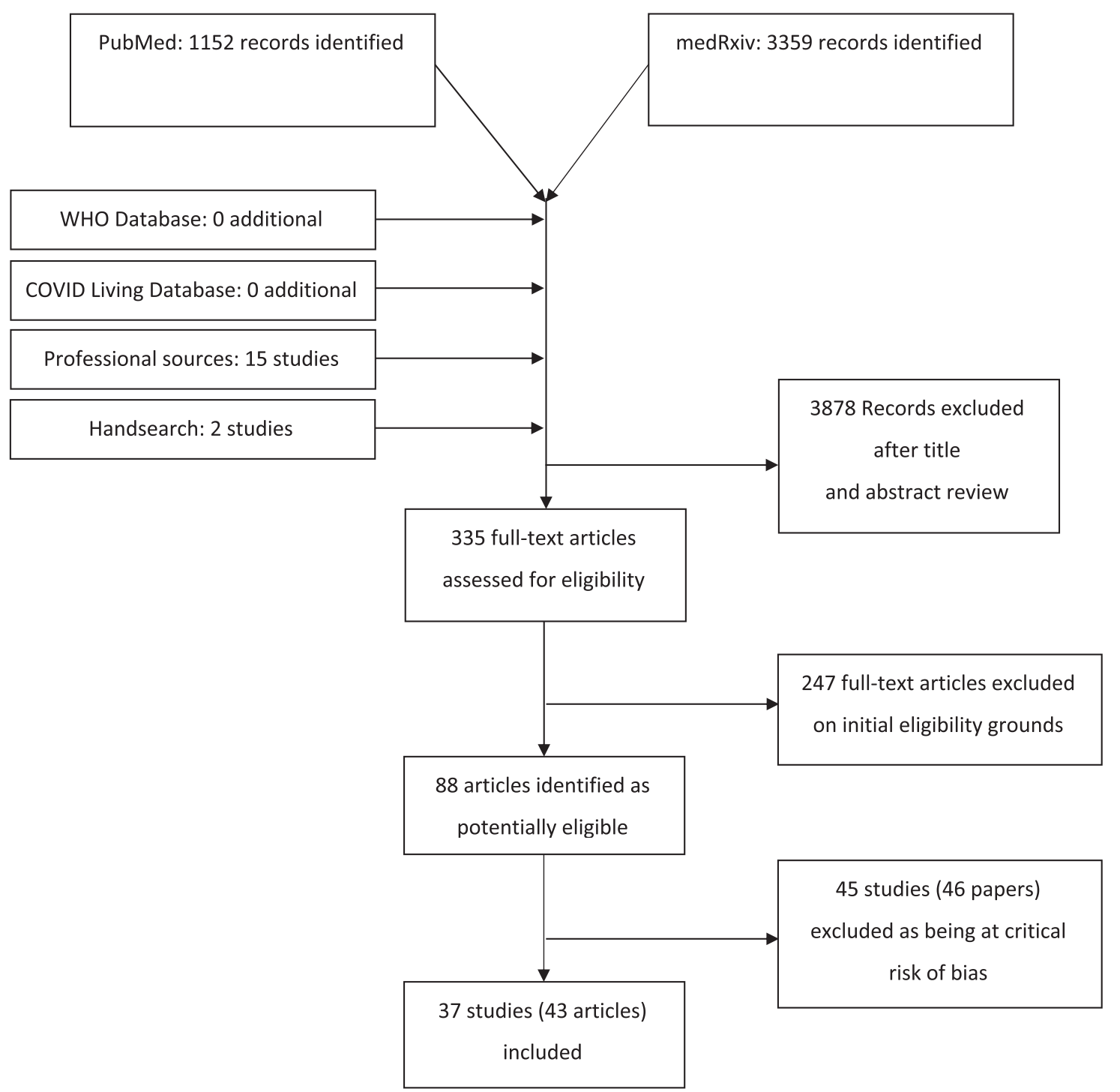

Fig. 1. FLOW diagram.

lands and Belgium, and 1 study each from Netherlands, Austria, Israel, India, Spain, and Australia.

Thirty-one studies (84\%) were undertaken before November 2020 and involved the wild-type virus, although only 2 explicitly reported this; 6 (16\%) studies included rounds with the alpha variant emerging (1) or dominant (5), with 2 (5\%) also including rounds in which the delta variant was emerging.

\section{Contact-tracing studies (household and school)}

Eighteen studies provided data on secondary infection or attack rates (SAR) from child index cases, including five large regional $^{2,31,32,35,37}$ and five national ${ }^{34,38,41,62,63}$ studies. Fifteen (8 household; 2,34,35,37-39,41,63 7 school $^{27-33,44}$ ) provided sufficient data to include in meta-analyses of secondary attack rates.
Forest plots of SAR from child index cases to all-age contacts are shown in Fig. 2 separately by setting. The pooled estimates of SAR were $7.6 \%(3.6,15.9)$ for household studies (panel A), significantly higher than the pooled estimate for school studies of $0.7 \%(0.2,2.7)$ (panel B) (difference $\mathrm{QM}(\mathrm{df}=1)=9.325, p=0.0023$ ).

Transmission from child index cases by age of contacts could be assessed in 4 school studies and 1 household study (Appendix Fig. 1). Pooled SAR to child contacts was not different to that to adult contacts $(p=0.45)$.

Odds of being a secondary case (of any age) from a child index compared with an adult index case were calculated from 11 rounds of data (6 household, 5 school; see Fig. 3). Across all studies, pooled risk of transmission was lower from child index cases than adults (OR $0.49(0.25,0.98)$; in sub-group analyses the OR was $0.27(0.06,1.28)$ for school studies and $0.72(0.45,1.16)$ for household studies, all with high heterogeneity. 
A: Household studies

Household: Secondary attack rate

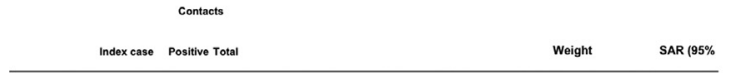

\begin{tabular}{|c|c|c|c|c|c|}
\hline Kim & 107 & 1 & 208 & $\longrightarrow$ & $7.118 \% 0.005[0.001,0.034]$ \\
\hline Hu & 25 & 2 & 193 & $\longmapsto$ & $9.478 \% 0.010[0.003,0.041]$ \\
\hline Li & 327 & 46 & 793 & + & $13.826 \% \quad 0.058[0.044,0.077]$ \\
\hline Laxminarayan & 6043 & 4110 & 57415 & - & $14.102 \% 0.072[0.070,0.074]$ \\
\hline Verberk & 39 & 17 & 131 & $F-1$ & $13.427 \% 0.130[0.083,0.202]$ \\
\hline Park & 153 & 46 & 288 & 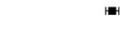 & $13.855 \% 0.160[0.123 .0 .208]$ \\
\hline Telle & 1498 & 740 & 4051 & - & $14.090 \% 0.183[0.171,0.195]$ \\
\hline Lyngse & 17991 & 10580 & 54292 & - & $14.104 \% 0.195[0.192,0.198]$ \\
\hline
\end{tabular}

Rese Model

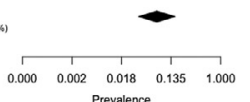

$100.000 \% 0.076[0.036,0.159]$

Panel B: School studies

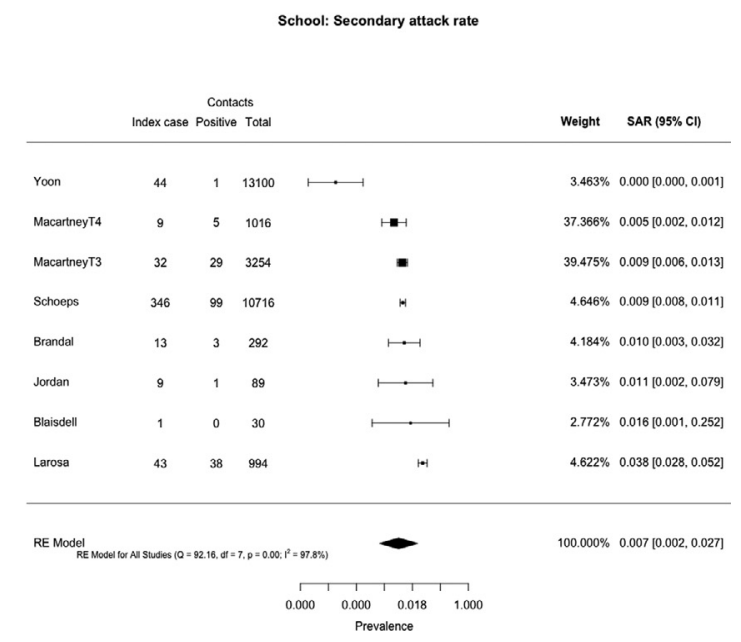

Fig. 2. Secondary attack rates from child index cases to all contacts for (A) household studies and (B) school contact-tracing studies.

\section{Odds of secondary cases from child index compared with adult index in household and school studies}

$\begin{array}{lll}\text { Child index } & \text { Adult index } & \text { Weight } \\ \text { positive total } & \text { positive total } & \end{array}$

OR $(95 \% \mathrm{Cl})$

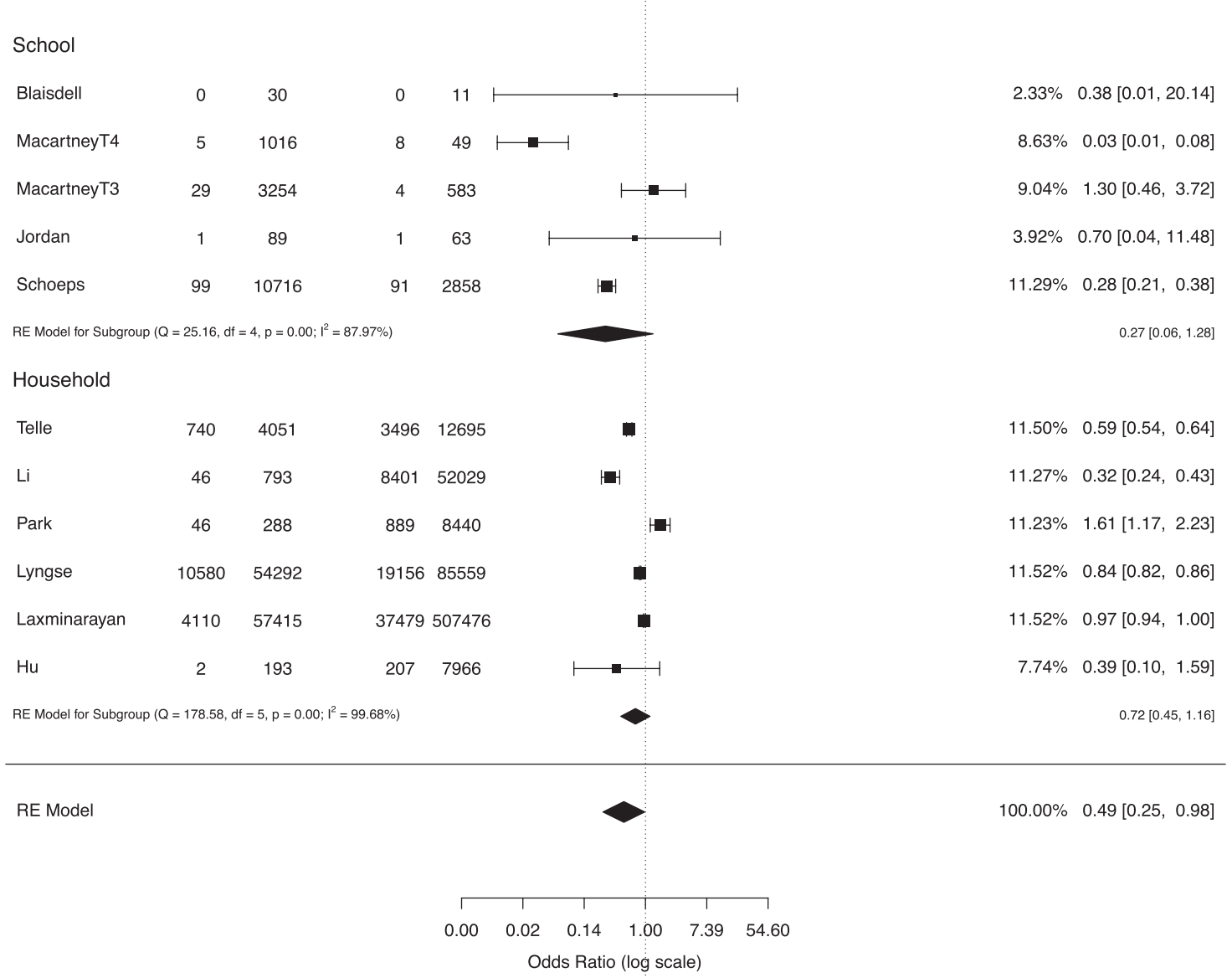

Fig. 3. Odds of being a secondary case from child compared with adult index cases. 
Relative transmissibility of children compared with adults: Household studies

Weight $\quad$ RR $(95 \% \mathrm{Cl})$

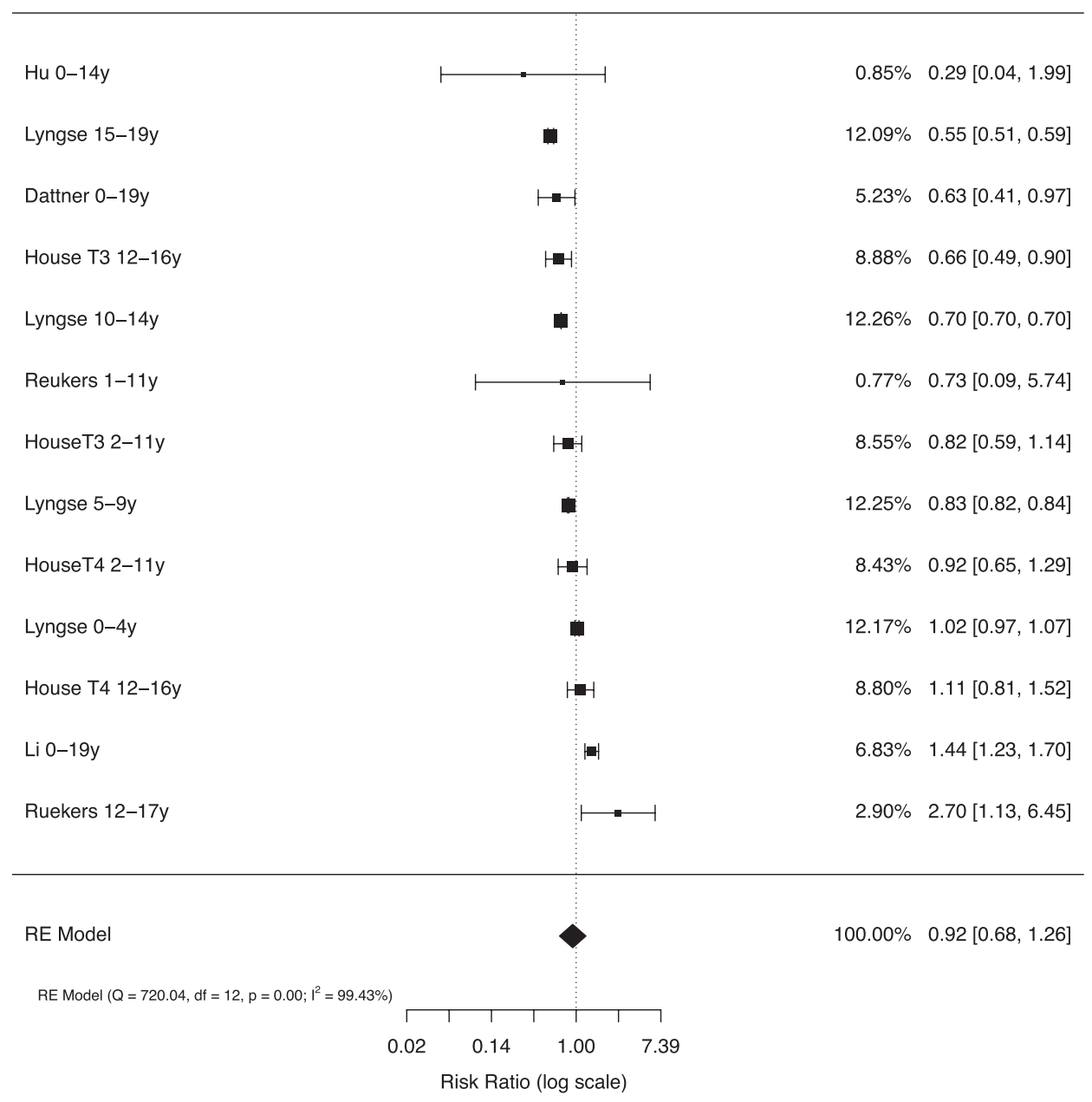

Fig. 4. Relative transmissibility of children and adolescents compared with adults in adjusted household models Note: Analysis includes the last two periods from House et al. and estimates by age from other studies.

Two studies could not be included in the meta-analyses. Varma et al. undertook a large school contact-tracing study from New York City ${ }^{43}$ and reported that the overall school SAR from CYP and adults was $0.5 \%$; of the $69 \%$ of secondary cases for which a source of infection could be identified, $51 \%$ were staff-to-staff, $27 \%$ staffto-student, $14 \%$ student-to-staff, and $8 \%$ from student-to-student. Espenhain et al. ${ }^{61}$ used data from 4 rounds of a Danish nationally representative community survey to examine transmission in 1244 households with resident adolescents. They reported that, in $73 \%$ of families with at least one seropositive family member, only the parent(s) or the child were seropositive, concluding that transmission between generations was uncommon.

\section{Adjusted household transmission models}

Six studies examined transmission from CYP to household members using adjusted transmission models accounting for a range of factors including individual exposure histories, potential tertiary transmission, poverty and the age-structure of popula- tions. Two studies used nationally representative data from England $^{60}$ and Denmark, ${ }^{41}$ and four were contact-tracing studies (from China, ${ }^{35,37}$ Israel $^{36}$ and the Netherlands ${ }^{40}$ ).

House et al. ${ }^{60}$ used longitudinal weekly PCR testing from a very large representative national sample of English household ${ }^{64}$ to estimate susceptible-infectious transmission probabilities from models in four periods from April 2020 to February 2021 across low and high prevalence, schools being reopened and the emergence of the alpha (B.1.1.7) variant in late 2020. They found transmissibility did not differ by age. However they did observe that the risk of bringing infection into household (relative external exposure) was higher amongst 12-16y than for adults although these included periods of national lockdown for adults whilst all children continued to attend full-time schooling. A Dutch contact-tracing study similarly concluded there were no differences in transmissibility between children and adults, ${ }^{40}$ whilst a large national Danish study ${ }^{41}$ and an Israeli contact-tracing study ${ }^{36}$ found lower relative transmissibility in children and young people compared to adults. Two contact-tracing studies from China found that, whilst in unadjusted analyses infected children generated fewer secondary cases than 
Panel A. PCR

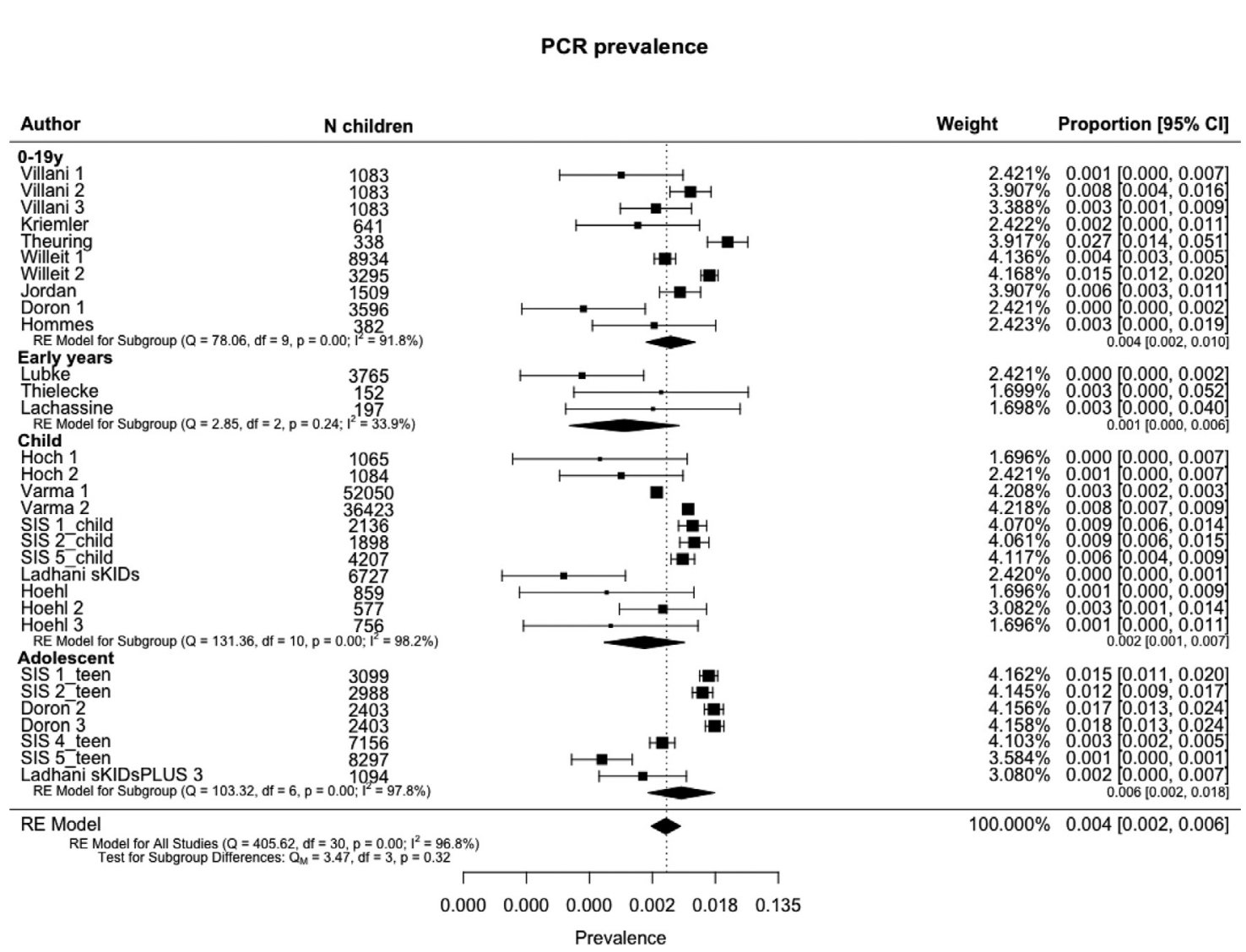

Fig. 5. Prevalence and seroprevalence of SARS-CoV-2 infection in schools by age-group: (A) PCR prevalence and (B) Seroprevalence.

adults, adjusted models showed no difference, ${ }^{35}$ or higher infectivity. ${ }^{37}$

Multilevel random-effects meta-analysis of relative transmissibility from CYP compared with adults included 13 estimates from 6 studies with total person-observations from 127,822

CYP and 1526,117 adults (Fig. 4). The pooled relative transmissibility from CYP was $0.92(0.68,1.26)$ compared with adults, with high heterogeneity (99.43\%). Data did not allow sub-group analyses by age of child.

\section{School prevalence studies}

Infection prevalence in schools or nurseries was measured in 16 studies (31 rounds of observations; total 161,280 childobservations) and antibody prevalence was measured in 9 studies (20 rounds; 26,509 child-observations). Some provided data for single age-groups (e.g. early-years, primary or secondary students) while others provided cross age-group data. In the main analyses, we used overall estimates where they exist and estimates by agegroup where the former were not provided.

Forest plots of PCR prevalence and seroprevalence by age are shown in Fig. 5. Meta-regression models are shown in Table 2. Pooled infection (PCR) prevalence across all studies was $0.4 \%(0.2$, $0.6)$, not significantly different by age-group $(p=0.32)$. Prevalence was also associated with contemporary community 14-day incidence (OR $1.003(1.001,1.004), p<0.001)$ and prevalence in the month prior to the study (OR $1.003(1.001,1.006), p=0.008$ ) but not with 2 months prior. PCR prevalence was not associated with school attendance rate nor PCR source. Plot of predicted school prevalence by 14-day incidence is shown across age-groups in Fig. 6.

Pooled seroprevalence across all studies was 4.8\% (2.4, 9.9), with no significant difference by age-group. Seroprevalence was associated with community incidence in the month and two months prior to the study, but not with contemporary incidence. Seroprevalence was not associated with school attendance.

No school studies fitted adjusted transmission models. Only two studies undertook a detailed analysis of clustering; Ulyte et al. ${ }^{9,65}$ reported that clusters of $\geq 3$ cases occurred in 7 of 129 classes in Round 2 and 24 of 119 in Round, more than the 4 and 17 classes expected by chance respectively. A very large school contacttracing study by Schoeps et al. ${ }^{28}$ reported that $83 \%$ of 784 school index cases led to no secondary cases. All other studies reported no evidence of clustering of infections (i.e. > 3-5 infections per class) within schools. ${ }^{10,46,47,51-56,59,66,67}$ Other observations supporting limited transmission in schools were calculations showing that where direction of transmission was available, the majority appeared to be from adults to children $28,43,49,51,68$ or that origins of transmission chains were outside schools; ${ }^{47}$ and observations that virus prevalence in school children and teachers was lower than in the local community at the time despite higher levels of testing within schools. ${ }^{43,52,53,67}$ Seroprevalence studies, however, reported similar antibody prevalence amongst students and teachers $^{54,67,68}$ or adults in the local community. 9,67,68

The association of school prevalence with community infection rates was examined in two school studies, both of which reported positive associations. ${ }^{43,56}$ Only one study examined associations of prevalence with social deprivation, reporting a positive association. ${ }^{56}$ 
Panel B. Seroprevalence

Seroprevalence

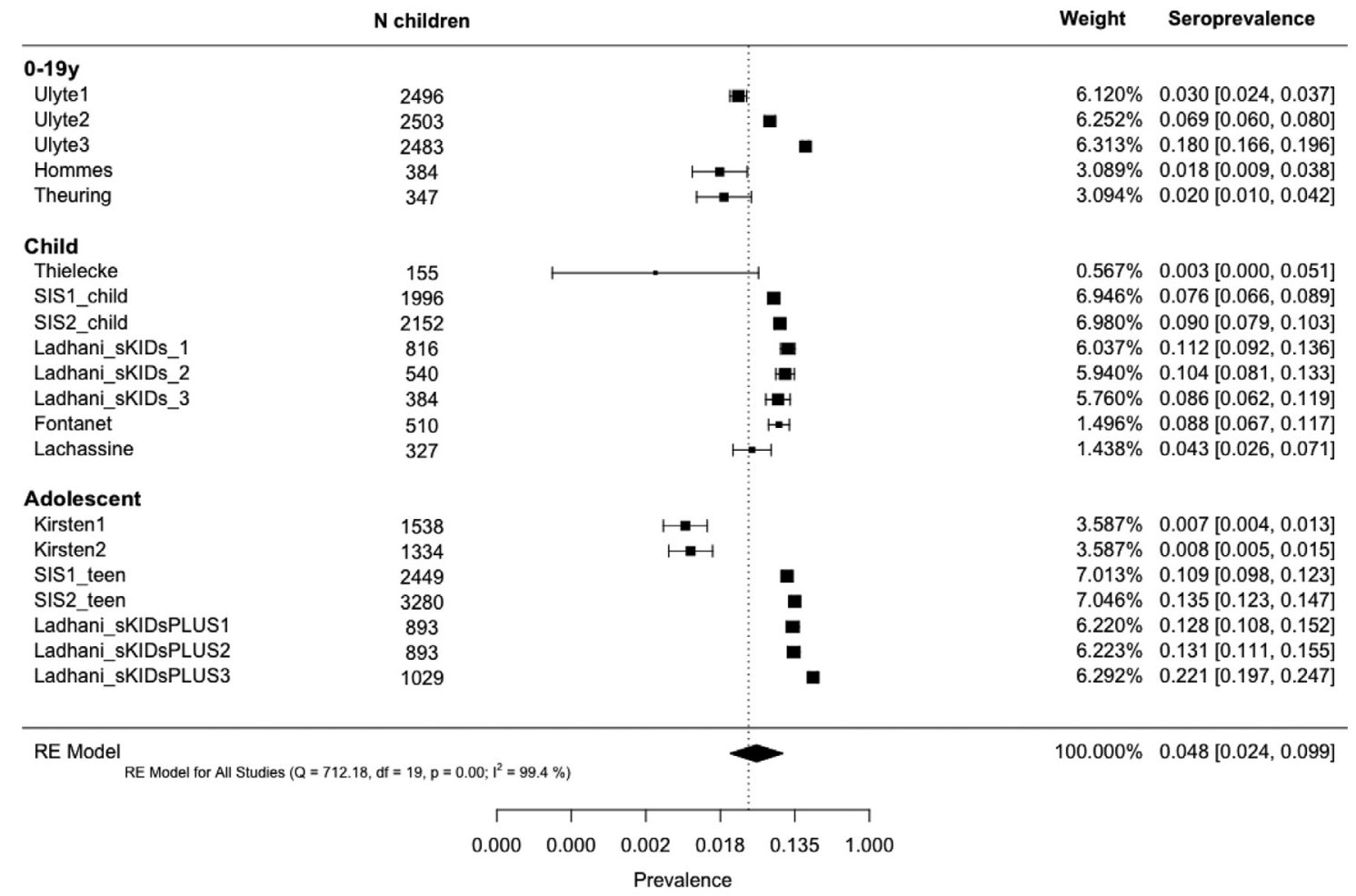

Fig. 5. Continued

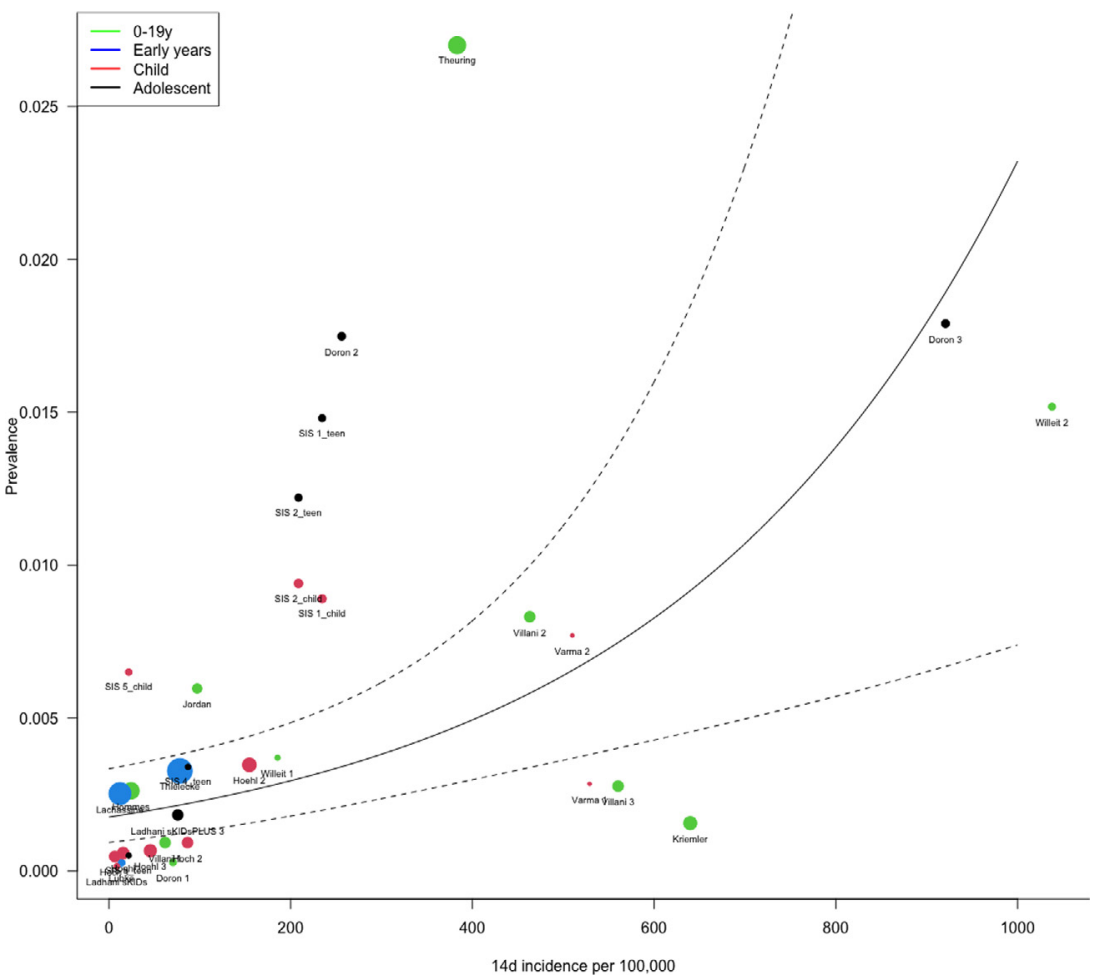

Fig. 6. Plot of predicted prevalence and $95 \% \mathrm{CI}$ in school studies by community 14-day incidence of SARS-CoV-2 infections per 100,000. 


\section{Discussion}

We report the first findings relating to SARS-CoV-2 transmission from CYP through meta-analysis of studies with low risk of bias. Meta-analysis of household studies which undertook adjusted transmission analyses showed no difference in relative transmissibility between CYP and adults (OR $0.92(0.68,1.26)$ ), although meta-analysis of unadjusted secondary attack rates suggested that transmission from CYP was lower than from adults, although with wide confidence intervals. There are a number of sources of potential bias in the unadjusted analyses, including low numbers of child index cases as well as differential transmission from children across generations of spread within households, and it is likely that these analyses under-estimate relative transmissibility. These findings suggest that, within households, CYP play a role in transmission that is to similar but not higher than adults. The only study to examine external force of infection suggests CYP play a role in bringing infection into the house when schools are open, but this included periods when the country was in lockdown whilst schools remained fully open. ${ }^{60}$

We found a striking difference in transmission from CYP across different settings, with the pooled SAR from CYP index cases in household studies (7.6\%) being 10-fold higher than in school studies $(0.7 \%)$, despite a similar quantity and quality of evidence in both settings. We were unable to draw conclusions about transmissibility from CYP compared with adults in educational settings, due to wide confidence intervals and lack of studies reporting adjusted analyses. We found no evidence that transmission differed from CYP index cases to contacts of differing ages. Similar to our findings, other studies have concluded that household settings have higher transmission potential than other settings such as schools. ${ }^{17,18}$ This disparity may reflect differences in the duration and intensity of social mixing within schools compared with households, with more prolonged, intense and intimate contacts between children and siblings or parents within households carrying a greater risk of transmission. ${ }^{69}$ Our findings may also reflect the successful operation of NPI mitigations within schools in markedly reducing transmission. ${ }^{70}$ This observation is supported by findings from some of the included school studies, including a lower prevalence in schools than in surrounding communities and the lack of notable clustering of infection within classrooms, even when local prevalence was high. Lack of clustering is supported by a number of studies not included in our review for quality reasons including a national study from Luxembourg. ${ }^{71}$ There may, however, be systematic bias that might contribute to lower transmission in school compared with household studies. For example, CYP who are known to be infected or are contacts of positive cases are usually excluded from school but would be included within household studies. However, a substantial proportion of infected CYP are likely to be asymptomatic and, therefore, unlikely to be absent from school. ${ }^{10}$ Biases related to relatively low numbers of CYP index cases, adequacy of contact-tracing and validity of PCR or serology testing in CYP apply equally to both school and household studies.

Our meta-regression findings that local community incidence was positively associated with school infection prevalence, as was incidence in the month prior, whereas seroprevalence was only associated with historical community incidence, show the interdependence of schools with their localities with respect to infection levels. Ismail et al. ${ }^{72}$ reported the risk of an outbreak increased by $72 \%$ for every five cases per 100000 population increase in community incidence, whilst Willeit et al. ${ }^{56}$ reported that the odds of testing positive in schools were $1.64(1.38,1.96)$ for a twofold higher community incidence. Our findings support the hypothesis that school infections predominantly reflect community infection levels, although our analysis could not attribute causality.
Our review included a number of studies undertaken when the prevalence of variants with higher transmissibility (e.g. alpha or B.1.1.7 variant) was rising or dominant, although most studies preceded this. No contact-tracing studies were included of transmission related to the delta variant although two school prevalence studies included data collection whilst delta infection was rising. Our findings therefore cannot be assumed to apply to periods when delta was predominant. However, whilst the delta variant has substantially higher overall transmissibility, and the prevalence of delta infection in children has been high at a time when adult populations had high vaccination coverage, there is no evidence of variant-specific differential transmission between children and adults. It is possible that the differential in transmission between school and household settings is lower for the higher transmissibility variants such as delta or omicron than reported here, although the higher transmissibility of the delta variant appears not to be setting-specific.

\section{Limitations}

Our data are subject to a number of limitations. Potential biases in school studies have been discussed above. RT-PCR studies may under-estimate infection in children compared with serology, ${ }^{36}$ and different seroassays may provide differing results. Many of the included studies, however, combined findings from both PCR and serology, $10,31,32,39,40,44,47,48,54,67$ or undertook repeated PCR measures ${ }^{40,44,45,49-51,53,60}$ Importantly, though, these issues are likely to be similar across both contact-tracing and population studies and, therefore, would not alter the notable differences we found by setting.

Contact-tracing studies are open to bias due to missed testing of contacts, although we only included those who planned routine testing of all contacts and who achieved a high proportion of contacts tested. Low numbers of child index cases and their contacts in some studies may also be a source of bias. Population studies may be biased by higher participation by higher socioeconomic status groups and also as some studies specifically excluded those with recent contacts or symptoms. ${ }^{50}$

We conducted multi-level analyses accounting for the nesting of multiple rounds of data-collection within single studies. Some of the smaller meta-analyses, however, may have been overly influenced by studies with many rounds of testing. Meta-regression analyses are conducted at study rather than individual level and are, therefore, subject to ecological biases and cannot infer causality.

Our findings relate largely to the original/Wuhan virus and the alpha variant and it is unclear how generalisable they will be to the delta or other variants. Paucity of data meant we were unable to compare transmissibility from CYP between the Wuhan and alpha variants. Additionally all data precede widespread vaccination of adults and no studies included populations of teenagers who had been vaccinated. Our data were largely limited to high-income countries and there is an urgent need for similar studies from lowand-middle-income countries.

\section{Conclusions and implications}

We found no difference in transmission of SARS-CoV-2 from CYP compared with adults within household settings. Secondary attack rates were markedly lower in school compared with household settings and there was little clustering of infections within schools, suggesting that household transmission is more high risk than school transmission in this pandemic.

School infection prevalence was associated with community infection incidence in the month before and during the study, with seroprevalence associated with historical community infections, 
supporting hypotheses that school infections broadly reflect community infections. These findings are important for guiding policy decisions on school operations during the pandemic. With appropriate mitigations, school infections can be limited and face-to-face learning is feasible, even at times of moderate to high community prevalence and in the presence of variants with higher transmissibility.

Our findings support a potential role for vaccination of CYP, if proven safe, in reducing transmission within households. Where countries go on to achieve very high levels of adult vaccination, this will focus transmission amongst the unvaccinated, increasing the relative importance of transmission amongst CYP.

Our findings largely relate to SARS-CoV-2 transmission from children before highly transmissible variants such as delta or omicron became predominant and this work needs replication once sufficient data are available from periods dominated by other variants. A number of other gaps in our knowledge remain about transmission from CYP, particularly relating to potential agedifferences between younger and older children, and effectiveness of various NPIs, especially face masks, to reduce transmission in child-specific settings. Detailed population studies are required which link households and schools and use a combination of repeated PCR and serology testing to assess the risk of infection and direction of transmission across settings.

\section{Contributions}

$\mathrm{RV}$ and $\mathrm{CB}$ conceptualised the paper and led the writing of the manuscript,RV undertook the searches, contributed to data extraction and quality assessment and undertook the meta-analyses. . $\mathrm{CW}, \mathrm{OM}, \mathrm{JC}$ and JW contributed to eligibility assessment, data extraction and quality assessment. GMT and CB contributed to planning the analyses. All authors contributed to writing and editing of the manuscript.

\section{Funding}

No funding obtained.

\section{Declaration of Competing Interests}

All authors declare no competing interests.

\section{Acknowledgments}

We thank Kjetil Telle, Norwegian Institute of Public Health, and Marieke de Hoog, University Medical Center Utrecht, for providing additional data for their studies included here. We also thank Semina Michalopoulou and Zainab Dedat for checking the accuracy of data extraction.

\section{Supplementary materials}

Supplementary material associated with this article can be found, in the online version, at doi:10.1016/j.jinf.2021.12.026.

\section{References}

1. Flasche S, Edmunds WJ. The role of schools and school-aged children in SARS-CoV-2 transmission. Lancet Infect Dis 2021;21(3):298-9 Epub 2020/12/08PubMed PMID: 33306982. doi:10.1016/S1473-3099(20)30927-0.

2. Laxminarayan R, Wahl B, Dudala SR, Gopal K, Mohan C, Neelima S, et al. Epidemiology and transmission dynamics of COVID-19 in two Indian states. Science 2020:eabd7672. doi:10.1126/science.abd7672.

3. Okarska-Napierala M, Mandziuk J, Kuchar E. SARS-CoV-2 cluster in nursery, Poland. Emerg Infect Dis 2021;27(1):PMCPMC7774538 Epub 2020/10/10PubMed PMID: 33035153PubMed Central PMCID. doi:10.3201/eid2701.203849.
4. Fontanet A, Tondeur L, Grant R, et al. SARS-CoV-2 infection in schools in a northern French city: a retrospective serological cohort study in an area of high transmission, France, January to April 2020. Euro Surveill. medRxiv preprint server 2021;26(15) Published E-Pub Apr. doi:10.2807/1560-7917.ES.2021.26.15. 2001695.

5. Torres JP, Pinera C, De La Maza V, Lagomarcino AJ, Simian D, Torres B, et al. SARS-CoV-2 antibody prevalence in blood in a large school community subject to a Covid-19 outbreak: a cross-sectional study. Clin Infect Dis 2020 Epub 2020/07/11PubMed PMID: 32649743. doi:10.1093/cid/ciaa955.

6. Stein-Zamir C, Abramson N, Shoob H, Libal E, Bitan M, Cardash T, et al. A large COVID-19 outbreak in a high school 10 days after schools' reopening, Israel, May 2020. Euro Surveill 2020;25(29) Epub 2020/07/29PubMed PMID: 32720636; PubMed Central PMCID: PMCPMC7384285. doi:10.2807/1560-7917.ES.2020.25. 29.2001352

7. Pray IW, Gibbons-Burgener SN, Rosenberg AZ, Cole D, Borenstein S, Bateman A, et al. COVID-19 outbreak at an overnight summer school retreat - Wisconsin, July-August 2020. MMWR Morb Mortal Wkly Rep 2020;69(43):1600-4 Epub 2020/10/30PubMed PMID: 33119558PubMed Central PMCID: PMCPMC7640998 Journal Editors form for disclosure of potential conflicts of interest. No other potential conflicts of interest were disclosed. doi:10.15585/mmwr.mm6943a4.

8. Szablewski CM, Chang KT, Brown MM, Chu VT, Yousaf AR, Anyalechi N, et al. SARS-CoV-2 transmission and infection among attendees of an overnight camp - Georgia, June 2020. MMWR Morb Mortal Wkly Rep 2020;69(31):1023-5 Epub 2020/08/08PubMed PMID: 32759921PubMed Central PMCID: PMCPMC7454898 Journal Editors form for disclosure of potential conflicts of interest. No potential conflicts of interest were disclosed. doi:10.15585/mmwr.mm6931e1.

9. Ulyte A, Radtke T, Abela IA, Haile SR, Berger C, Huber M, et al. Clustering and longitudinal change in SARS-CoV-2 seroprevalence in school children in the canton of Zurich, Switzerland: prospective cohort study of 55 schools. BMJ 2021;372 n616. Epub 2021/03/19PubMed PMID: 33731327; PubMed Central PMCID: PMCPMC7966948 at www.icmje.org/coi_disclosure.pdf and declare: support from Swiss School of Public Health (SSPH+), Swiss Federal Office of Public Health, private funders, funds of the cantons of Switzerland (Vaud, Zurich, and Basel), institutional funds of universities, and University of Zurich Foundation for the submitted work; no financial relationships with any organisations that might have an interest in the submitted work in the previous three years; no other relationships or activities that could appear to have influenced the submitted work. doi:10.1136/bmj.n616.

10. Ladhani SN, Baawuah F, Beckmann J, Okike IO, Ahmad S, Garstang J, et al. SARS-CoV-2 infection and transmission in primary schools in England in JuneDecember 2020 (sKIDs): an active, prospective surveillance study. Lancet Child Adolesc Health 2021 Epub 2021/03/20PubMed PMID: 33740430. doi:10.1016/ S2352-4642(21)00061-4.

11. Viner RM, Mytton OT, Bonell C, Melendez-Torres GJ, Ward J, Hudson L, et al Susceptibility to SARS-CoV-2 infection among children and adolescents compared with adults: a systematic review and meta-analysis. JAMA Pediatr 2020 Epub 2020/09/26PubMed PMID: 32975552. doi:10.1001/jamapediatrics.2020. 4573.

12. Jarvis C, Munday J, Gimma A, Wong K, Van Zandvoort K, Funk S, et al. Social contacts in the UK from the CoMix Social Contact Survey: Report For Survey Week 61. London School of Tropical Medicine and Hygiene; 2021. 1 June 2021. Report No.

13. Suk JE, Vardavas C, Nikitara K, Phalkey R, Leonardi-Bee J, Pharris A, et al. The role of children in the transmission chain of SARS-CoV-2: a systematic review and update of current evidence. medRxiv 9 Nov 2020 2020.11.06.20227264. doi:10.1101/2020.11.06.20227264.

14. Gaythorpe KAM, Bhatia S, Mangal T, Unwin HJ, Imai N, et al. Children's role in the COVID-19 pandemic: a systematic review of early surveillance data on susceptibility, severity, and transmissibility. Scientific reports 2021;11(1):13903 Published E-Pub. doi:10.1038/s41598-021-92500-9.

15. Xu W, Li X, Dozier M, He Y, Kirolos A, Lang Z, et al. What is the evidence for transmission of COVID-19 by children in schools? A living systematic review. medRxiv 14 oct 2020 2020.10.11.20210658. doi:10.1101/2020.10.11.20210658.

16. Spielberger BD, Goerne T, Geweniger A, Henneke P, Elling R. Intra-household and close-contact SARS-CoV-2 transmission among children - a systematic review. Front Pediatr 2021;9:PMCPMC8062727 613292Epub 2021/04/27PubMed PMID: 33898355; PubMed Central PMCID. doi:10.3389/fped.2021.613292.

17. Madewell ZJ, Yang Y, Longini IM Jr, Halloran ME, Dean NE. Household transmission of SARS-CoV-2: a systematic review and meta-analysis. JAMA Netw Open 2020;3(12) e2031756-ePubMed PMID: 33315116. doi:10.1001/jamanetworkopen. 2020.31756

18. Thompson HA, Mousa A, Dighe A, Fu H, Arnedo-Pena A, Barrett P, et al. SARS-CoV-2 setting-specific transmission rates: a systematic review and metaanalysis. Clin Infect Dis Off Publ Infect Dis Soc Am 2021:ciab100 PubMed PMID: 33560412. doi:10.1093/cid/ciab100.

19. Krishnaratne S, Pfadenhauer LM, Coenen M, Geffert K, Jung-Sievers C, Klinger C, et al. Measures implemented in the school setting to contain the COVID-19 pandemic: a rapid scoping review. Cochr Database Syst Rev 2020(12) PubMed PMID: CD013812. doi:10.1002/14651858.CD013812.

20. Stuart EA, Dowdy DW. Evidence-based COVID-19 policy-making in schools. Nat Med 2021. doi:10.1038/s41591-021-01585-2.

21. Haag L, Blankenburg J, Unrath M, Grabietz J, Kahre E, Galow L, et al. Prevalence and transmission of SARS-CoV-2 in childcare facilities: a longitudinal study. medRxiv 18 April 2021 2021.04.16.21255616. doi:10.1101/2021.04.16.21255616.

22. Walsh S, Chowdhury A, Braithwaite V, et al. Do school closures and school reopenings affect community transmission of COVID-19? A systematic review of 
observational studies. BMJ open 2021;11(8):e053371 Published E-Pub Aug 17. doi:10.1136/bmjopen-2021-053371.

23. Checklist For Prevalence studies: The Joanna Briggs Institute Critical Appraisal Tools For Use in JBI Systematic Reviews. Adelaide, South Australia: Joanna Briggs Institute; 2017

24. Munn Z, Moola S, Lisy K, Riitano D, Tufanaru C. Methodological guidance for systematic reviews of observational epidemiological studies reporting prevalence and cumulative incidence data. Int J Evid Based Healthc 2015;13(3):147-53 Epub 2015/09/01PubMed PMID: 26317388. doi:10.1097/XEB. 0000000000000054

25. Loney PL, Chambers LW, Bennett KJ, Roberts JG, Stratford PW. Critical appraisal of the health research literature: prevalence or incidence of a health problem. Chronic Dis Can 1998;19(4):170-6 Epub 1999/02/24. PubMed PMID: 10029513.

26. Moola S, Munn Z, Tufanaru C, Aromataris E, Sears K, Sfetcu R, et al. Systematic reviews of etiology and risk JBI Manual for Evidence Synthesis Aromataris E, Munn Z, editors. JBI; 2020.

27. Blaisdell LL, Cohn W, Pavell JR, Rubin DS, Vergales JE. Preventing and mitigating SARS-CoV-2 transmission - four overnight camps, Maine, June-August 2020. MMWR Morb Mort Wkly Rep 2020;69(35):1216-20 PubMed PMID: 32881850. doi:10.15585/mmwr.mm6935e1.

28. Schoeps A, Hoffmann D, Tamm C, Vollmer B, Haag S, Kaffenberger T, et al. COVID-19 transmission in educational institutions August to December 2020 in Germany: a study of index cases and close contact cohorts. medRxiv 2021 2021.02.04.21250670. doi:10.1101/2021.02.04.21250670.

29. Yoon Y, Kim KR, Park H, Kim S, Kim YJ. Stepwise school opening and an impact on the epidemiology of COVID-19 in the children. J Korean Med Sci 2020;35(46):e414 Epub 2020/12/02. doi: 10.3346/jkms.2020.35.e414. PubMed PMID: 33258334; PubMed Central PMCID: PMCPMC7707922.

30. Larosa E, Djuric O, Cassinadri M, Cilloni S, Bisaccia E, Vicentini M, et al. Secondary transmission of COVID-19 in preschool and school settings in northern Italy after their reopening in September 2020: a population-based study. Euro Surveill 2020;25(49) PubMed PMID: 33303065; PubMed Central PMCID: PMCPMC7730487. doi:10.2807/1560-7917.ES.2020.25.49.2001911

31. National Centre for Immunisation Research and Surveillance or NCIRS. COVID-19 in Schools and Early Childhood Education and Care Services - the Term 3 experience in NSW, Sydney, Australia: National Centre for Immunisation Research and Surveillance; 2020. 21 October 2020. Report No.

32. National Centre for Immunisation Research and Surveillance or NCIRS. COVID-19 in Schools and Early Childhood Education and Care Services - the Term 4 experience in NSW, Sydney, Australia: National Centre for Immunisation Research and Surveillance; 2021. 9 March 2021 Report No.

33. Brandal LT, Ofitserova TS, Meijerink H, Rykkvin R, Lund HM, Hungnes O, et al. Minimal transmission of SARS-CoV-2 from paediatric COVID-19 cases in primary schools, Norway, August to November 2020. Euro surveill: Bull Eur Malad Trans = Eur Commun Dis Bull 2021;26(1) 2002011PubMed PMID: 33413743. doi:10.2807/1560-7917.ES.2020.26.1.2002011.

34. Park YJ, Choe YJ, Park O, Park SY, Kim YM, Kim J, et al. Contact tracing during coronavirus disease outbreak, South Korea,. Emerg Infect Dis 2020;26(10) Epub 2020/07/17PubMed PMID: 32673193 doi:10.3201/eid2610.201315.

35. Hu S, Wang W, Wang Y, Litvinova M, Luo K, Ren L, et al. Infectivity, susceptibility, and risk factors associated with SARS-CoV-2 transmission under intensive contact tracing in Hunan, China. Nat Commun 2021;12(1):1533 Epub 2021/03/23. doiPubMed PMID: 33750783; PubMed Central PMCID: PMCPMC7943579 Seqirus, and H.Y. has received research funding from Sanofi Pasteur, GlaxoSmithKline, Yichang HEC Changjiang Pharmaceutical Company, and Shanghai Roche Pharmaceutical Company. None of those research funding is related to COVID-19. All other authors report no competing interests. doi:10.1038/s41467-021-21710-6.

36. Dattner I, Goldberg Y, Katriel G, Yaari R, Gal N, Miron Y, et al. The role of children in the spread of COVID-19: using household data from Bnei Brak, Israel, to estimate the relative susceptibility and infectivity of children. PLoS Comput Biol 2021;17(2) e1008559-ePubMed PMID: 33571188. doi:10.1371/journal.pcbi. 1008559

37. Li F, Li Y-Y, Liu M-J, Fang L-Q, Dean NE, Wong GWK, et al. Household transmission of SARS-CoV-2 and risk factors for susceptibility and infectivity in Wuhan: a retrospective observational study. Lancet Infect Dis 2021. doi:10.1016/ S1473-3099(20)30981-6.

38. Kim J, Choe YJ, Lee J, Park YJ, Park O, Han MS, et al. Role of children in household transmission of COVID-19. Arch Dis Child 2020 Epub 2020/08/10PubMed PMID: 32769089. doi:10.1136/archdischild-2020-319910.

39. Verberk J, de Hoog M, Westerhof I, Van Goethem S, Lammens C, Ieven M, et al. Transmission of SARS-CoV-2 within households: a prospective cohort study in the Netherlands and Belgium - Interim results. medRxiv 2021 2021.04.23.21255846. doi:10.1101/2021.04.23.21255846.

40. Reukers DFM, van Boven M, Meijer A, Rots N, Reusken C, Roof I, et al. High infection secondary attack rates of SARS-CoV-2 in Dutch households revealed by dense sampling. Clin Infect Dis 2021:PMCPMC8083540 Epub 2021/04/07PubMed PMID: 33822007; PubMed Central PMCID:. doi:10.1093/cid/ciab237.

41. Lyngse FP, Mølbak K, Træholt Frank K, Nielsen C, Skov RL, Kirkeby CT. Association between SARS-CoV-2 transmission risk, viral load, and age: a nationwide study in danish households. medRxiv 2021 2021.02.28.21252608. doi:10. $1101 / 2021.02 .28 .21252608$

42. Telle K, Jørgensen SB, Hart R, Greve-Isdahl M, Kacelnik O. Secondary attack rates of COVID-19 in Norwegian families: a nation-wide register-based study. Eur J Epidemiol 2021:1-8 PubMed PMID: 34036466. doi:10.1007| s10654-021-00760-6.
43. Varma JK, Thamkittikasem J, Whittemore K, Alexander M, Stephens DH, Arslanian $\mathrm{K}$, et al. COVID-19 infections among students and staff in New York City public schools. Pediatrics 2021:e2021050605. doi:10.1542/peds.2021-050605.

44. Jordan I, de Sevilla MF, Fumado V, Bassat Q, Bonet-Carne E, Fortuny C, et al. Transmission of SARS-CoV-2 infection among children in summer schools applying stringent control measures in Barcelona, Spain. Clin Infect Dis 2021. doi:10.1093/cid/ciab227.

45. Hoehl S, Kreutzer E, Schenk B, Westhaus S, Foppa I, Herrmann E, et al. Longitudinal testing for respiratory and gastrointestinal shedding of SARS-CoV-2 in day care centres in Hesse, Germany. Clin Infect Dis 2021 Epub 2021/01/04PubMed PMID: 33388748; PubMed Central PMCID: PMCPMC7799213. doi:10.1093/cid/ ciaa1912.

46. Kriemler S, Ulyte A, Ammann P, Peralta GP, Berger C, Puhan MA, et al. Surveillance of acute SARS-CoV-2 infections in school children and point-prevalence during a time of high community transmission in Switzerland. Front Pediatr 2021;9:645577 Epub 2021/04/03PubMed PMID: 33796490; PubMed Central PMCID: PMCPMC8007924. doi:10.3389/fped.2021.645577.

47. Theuring S, Thielecke M, van Loon W, Hommes F, Hülso C, von der Haar A, et al. SARS-CoV-2 infection and transmission in school settings during the second wave in Berlin, Germany: a cross-sectional study. medRxiv 2021 2021.01.27.21250517. doi:10.1101/2021.01.27.21250517.

48. Thielecke M, Theuring S, van Loon W, Hommes F, Mall MA, Rosen A, et al. SARSCoV-2 infections in kindergartens and associated households at the start of the second wave in Berlin, Germany - a cross sectional study. Eur J Public Health 2021:ckab079 PubMed PMID: 33956945. doi:10.1093/eurpub/ckab079.

49. Hoch M, Vogel S, Kolberg L, Dick E, Fingerle V, Eberle U, et al. Weekly SARS-CoV-2 sentinel surveillance in primary schools, kindergartens, and nurseries, Germany, June-November 2020. Emerg Infect Dis 2021;27(8) Epub 2021/06/05PubMed PMID: 34087088. doi:10.3201/eid2708.204859.

50. Lübke N, Schupp A-K, Bredahl R, Kraus U, Hauka S, Andrée M, et al. Screening for SARS-CoV-2 infections in daycare facilities for children in a large city in Germany. medRxiv 2021 2021.02.26.21252510. doi:10.1101/2021.02.26.21252510.

51. Doron S, Ingalls RR, Beauchamp A, Boehm J, Boucher HW, Chow LH, et al. Weekly SARS-CoV-2 screening of asymptomatic students and staff to guide and evaluate strategies for safer in-person learning. medRxiv 2021 2021.03.20.21253976. doi:10.1101/2021.03.20.21253976.

52. . COVID-19 Schools Infection Survey Round 1, England, England: Office for National Statistics (ONS); 2020. November 202017 Dec 2020. Report No.

53. Villani A, Coltella L, Ranno S, Bianchi di Castelbianco F, Murru PM, Sonnino R, et al. School in Italy: a safe place for children and adolescents. Ital J Pediatr 2021;47(1):23 Epub 2021/02/0410.1186/s13052-021-00978-w. PubMed PMID: 33531046; PubMed Central PMCID: PMCPMC7851807.

54. Hommes F, van Loon W, Thielecke M, Abramovich I, Lieber S, Hammerich $R$, et al. SARS-CoV-2 infection, risk perception, behaviour and preventive measures at schools in Berlin, Germany, during the early post-lockdown phase: a cross-sectional study. Int J Environ Res Public Health 2021;18(5) Epub 2021/04/04PubMed PMID: 33800392; PubMed Central PMCID: PMCPMC7967466. doi:10.3390/ijerph18052739.

55. Kirsten C, Unrath M, Lück C, Dalpke AH, Berner R, Armann J. SARS-CoV-2 seroprevalence in students and teachers: a longitudinal study from May to October 2020 in German secondary schools. BMJ Open 2021;11(6):e049876 Epub 2021/06/12PubMed PMID: 34112645; PubMed Central PMCID: PMCPMC8193693. doi:10.1136/bmjopen-2021-049876.

56. Willeit P, Krause R, Lamprecht B, Berghold A, Hanson B, Stelzl E, et al. Prevalence of RT-qPCR-detected SARS-CoV-2 infection at schools: first results from the Austrian School-SARS-CoV-2 prospective cohort study. Lancet Reg Health Europe 2021;5:100086. doi:10.1016/j.lanepe.2021.100086.

57. Fontanet A, Tondeur L, Grant R, Temmam S, Madec Y, Bigot T, et al. SARS-CoV-2 infection in schools in a northern French city: a retrospective serological cohort study in an area of high transmission, France, January to April 2020. Euro Surveill 2021;26(15) Epub 2021/04/17PubMed PMID: 33860747; PubMed Central PMCID: PMCPMC8167414. doi:10.2807/1560-7917.ES.2021.26.15.2001695.

58. Lachassinne E, de Pontual L, Caseris M, Lorrot M, Guilluy C, Naud A, et al. SARS-CoV-2 transmission among children and staff in daycare centres during a nationwide lockdown in France: a cross-sectional, multicentre, seroprevalence study. Lancet Child Adolesc Health 2021;5(4):256-64. doi:10.1016/ S2352-4642(21)00024-9.

59. Ladhani SN, Ireland G, Baawuah F, Beckmann J, Okike IO, Ahmad S, et al. Emergence of SARS-CoV-2 Alpha (B.1.1.7) variant, infection rates, antibody seroconversion and seroprevalence rates in secondary school students and staff: active prospective surveillance, December 2020 to March 2021, England. medRxiv 2021 2021.07.14.21260496. doi:10.1101/2021.07.14.21260496.

60. House T., Pellis L., Pouwels K.B., Bacon S., Eidukas A., Jahanshahi K., et al. Inferring risks of coronavirus transmission from community household Data2021 April 01, 2021: [arXiv:2104.04605 p.]. Available from: https://ui.adsabs.harvard. edu/abs/2021arXiv210404605H.

61. Espenhain L, Tribler S, Jørgensen CS. Holm Hansen C, Wolff Sönksen U Ethelberg S. Prevalence of SARS-CoV-2 antibodies in Denmark 2020: results from nationwide, population-based sero-epidemiological surveys. medRxiv 2021 2021.04.07.21254703. doi:10.1101/2021.04.07.21254703.

62. Yoon Y, Kim K-R, Park H, Sy Kim, Kim Y-J. Stepwise school opening online and off-line and an impact on the epidemiology of COVID-19 in the pediatric population. medRxiv 2020 2020.08.03.20165589. doi:10.1101/2020.08.03.20165589.

63. Telle K, Jørgensen SB, Hart R, Greve-Isdahl M, Kacelnik O. Secondary attack rates of COVID-19 in Norwegian families: a nation-wide register-based study. medRxiv 2021 2021.03.06.21252832. doi:10.1101/2021.03.06.21252832. 
64. . COVID-19 Infection Survey: Methods and Further Information, England: Office for National Statistics (ONS); 2021. 26 March 2021. Report No.

65. Ulyte A, Radtke T, Abela IA, Haile SR, Ammann P, Berger C, et al. Evolution of SARS-CoV-2 seroprevalence and clusters in school children from June 2020 to April 2021 reflect community transmission: prospective cohort study Ciao Corona. medRxiv 2021 2021.07.19.21260644. doi:10.1101/2021.07.19.21260644.

66. Thielecke M, Theuring S, van Loon W, Hommes F, Mall MA, Rosen A, et al. SARS-CoV-2 infections in kindergartens and associated households at the start of the second wave in Berlin, Germany - a cross sectional study. medRxiv 2020 2020.12.08.20245910. doi:10.1101/2020.12.08.20245910.

67. COVID-19 Schools Infection Survey Rounds 2 to 5. England: office for National Statistics (ONS), 2021 July 2021. Report No.

68. Fontanet A, Grant R, Tondeur L, Madec Y, Grzelak L, Cailleau I, et al. SARS-CoV-2 infection in primary schools in northern France: a retrospective cohort study in an area of high transmission. medRxiv 2020 2020.06.25.20140178. doi:10.1101/ 2020.06.25.20140178.

69. Mossong J, Hens N, Jit M, Beutels P, Auranen K, Mikolajczyk R, et al. Social contacts and mixing patterns relevant to the spread of infectious diseases. PLoS
Med 2008;5(3):e74 Epub 2008/03/28PubMed PMID: 18366252; PubMed Central PMCID: PMCPMC2270306. doi:10.1371/journal.pmed.0050074.

70. Lessler J, Grabowski MK, Grantz KH, Badillo-Goicoechea E, Metcalf CJE, Lupton-Smith C, et al. Household COVID-19 risk and in-person schooling. Science 2021;372(6546):1092-7 Epub 2021/05/01. doi: 10.1126/science.abh2939. PubMed PMID: 33927057; PubMed Central PMCID: PMCPMC8168618.

71. Mossong J, Mombaerts L, Veiber L, Pastore J, Coroller GL, Schnell M, et al. SARSCoV-2 transmission in educational settings during an early summer epidemic wave in Luxembourg. BMC Infect Dis 2021;21(1):417 Epub 2021/05/06PubMed PMID: 33947340; PubMed Central PMCID: PMCPMC8093902. doi:10.1186/ s12879-021-06089-5.

72. Ismail S.A., Saliba V., Lopez Bernal J., Ramsay M.E., Ladhani S.N. SARS-CoV2 infection and transmission in educational settings: a prospective, crosssectional analysis of infection clusters and outbreaks in England. Lancet Infect Dis 2021;21(3):344-53. Epub 2020/12/08. doi: 10.1016/S1473-3099(20)30882-3. PubMed PMID: 33306981. 